(Aus der I. med. Klinik in Wien [Vorstand Prof. Wenckebach].)

\title{
Zur Kenntnis und Analyse der periodischen Herztätigkeit beim Menschen.
}

\author{
Von \\ H. Winterberg. \\ Mit 3 Tafeln. \\ (Eingegangen am 25. Juni 1919.)
}

Schwankungen des Herzrhythmus von größerer oder geringerer Regelmäßigkeit sind eine keineswegs seltene klinische Erscheinung. Sie lassen sich meist leicht auf respiratorische Arhythmie, Extrasystolen oder auf periodischen bzw. rhythmischen Ausfall von Kammer- bzw. Vorhofsystolen zurückführen. Außer diesen wohlbekannten und verhältnismäßig leicht analysierbaren Formen ist durch Wenckebach ${ }^{1}$ ) auch das Vorkommen von sog. ,L ucianischen Perioden“ beim Menschen bekannt geworden. Bei dem Falle, über den im folgenden berichtet werden soll, waren wir lange im Zweifel, ob er nicht als Analogon der sonst nur noch bei Sterbenden von Robinso ${ }^{2}$ ) beschriebenen $\mathrm{Lu}$ cianischen Perioden anzusehen sei. Es bedurfte einer eingehenden klinisch experimentellen Analyse, um zu einer bestimmten und genügend gesicherten Auffassung zu gelangen.

\section{Vorgeschichte.}

Es handelt sich um einen 20 Jahre alten ledigen Zugsführer M. L., der nachstehende selbstverfaßte Angaben macht: „Meine Eltern und Geschwister leben und sind gesund. Als Kind war ich mittelstark, mit 6 Jahren hatte ich Masern, mit 7 Jahren Blattern. Beide Krankheiten hatten keine Nacherscheinungen. Zwischen 10 und 15 Jahren war ich leidenschaftlicher Fußballspieler. Während und nach dem Spiele hatte ich immer starkes Herzklopfen und Schwäche. Damals hat mir auch ein Arzt Ruhe empfohlen, was ich befolgte. Das Schwäche-

1) Wenckebach, Beiträge zur Kenntnis der menschlichen Herzstätigkeit. 3. Teil. Über am menschlichen Herzen beobachtete Lucianische Perioden. Archiv f. Anat. u. Physiol. Suppl. S. 67.

2) Robinson, A study with the Electrocardiograph of the mode of death of the human heart. Journ. of experim. Med. 16, 291. 1912.

Z. f. d. g. exp. Med. X. 
gefühl, das ich immer während des Herumlaufens empfand, ist darauf gänzlich verschwunden. Im Mai 1916 rückte ich zum Militär ein. Im Felde haben sich die Schwächebeschwerden wiederholt, besonders nach Märschen mit Rüstung. Uberdies traten sehr oft Magenbeschwerden mit Durchfall auf. Die ersten größeren Herzbeschwerden hatte ich im Juni 1917. Ich fühlte immer einen Druck in der Herzgegend und litt sehr oft an Schwindelanfällen. Im September kam ich infolge meines Zustandes in ein Feldspital. Die Schwindelanfälle wiederholten sich hier noch einige Zeit bis zu meiner Transferierung ins Krieg̀sspital Grinzing. Ich trinke keine geistigen Getränke und rauche nicht."

\section{Befund bei der A ufnahme.}

Nach zweimonatigem Aufenthalt in Grinzing wurde der Patient zwecks Konstatierung seines Herzleidens auf die I. med. Klinik aufgenommen und stand daselbst vom 29. XI. 1917 bis zum 6. VIII. 1918 von einigen Urlaubsunterbrechungen abgesehen in ständiger Beobachtung. Er präsentiert sich als kräftiger, schlanker Mann von mittlerer Größe und $65 \mathrm{~kg}$ Körpergewicht. Die Organuntersuchung ergibt durchaus normale Verhältnisse. Auch das Herz ist in seinen Dimensionen nicht vergrößert, der orthodiagraphische Transversaldurchmesser mißt $10^{1} / 2 \mathrm{~cm}$. (Mr. $\left.=5+\mathrm{Ml} .=5^{1 / 2} \mathrm{~cm}\right)$, der Längsdurchmesser $11 \mathrm{~cm}$. Die Herzfigur zeigt außer der etwas stärkeren Vorwölbung des rechten Vorhofes nichts Auffälliges, insbesondere fehlt jedes Zeichen mitraler Konfiguration bzw. einer vermehrten Füllung des linken Vorhofes. Die Töne sind an allen Ostien gut begrenzt, aber auffallend leise. Der Gefäßstamm ist schlank, der Blutdruck erreicht systolisch $115 \mathrm{~mm} \mathrm{Hg-Höhe} \mathrm{(R.} \mathrm{R.).} \mathrm{Die} \mathrm{sofort} \mathrm{die} \mathrm{Aufmerksamkeit}$ fesselnde und am meisten charakteristische Erscheinung, die sowohl beim Auscultieren des Herzens wie bei der Palpation des Pulses aufs deutlichste hervortritt, ist eine eigentümliche periodische Herztätigkeit. Sie besteht darin, daß beständig und in ziemlich regelmäßiger Weise Gruppen sehr frequenter Herzschläge mit 2-3 langsamen Pulsen wechseln.

Elektrographischer Befund ${ }^{\mathfrak{y}}$ ) und Periodenbau.

Das Ekg. des Patienten bot, von der in die Augen springenden Gruppenbildung abgesehen, nichts besonders Erwähnenswertes. P, $\mathrm{R}$ und $\mathrm{T}$ sind in allen Ableitungen positiv, ebenso findet sich in allen

1) Die elektrographischen Aufnahmen sind mit dem großen Modell des Edel. manschen Galvanometers (Saitenspannung $=1 \mathrm{~cm}$ für 1 Millivolt) bei eingeschaltetem Kondensator gewonnen. Doch wurde die Eichung nicht jedesmal nachgeprüft, so daß sich unter den reproduzierten Kurven auch solche finden, die mit etwas größerer oder geringerer Saitenempfindlichkeit geschrieben sind. 
Ableitungen eine aus dem absteigenden Aste von $R$ direkt herauswachsende S-Zacke. Da alle Details in Abl. II (r. Hand, 1. Fuß) am deutlichsten ausgebildet waren, wurde bei der fortlaufenden elektrographischen Kontrolle diese Ableitung fast ausschließlich benützt. Ihr entsprechen auch alle Abbildungen. Um zunächst von der Art der Periodenbildung einen allgemeinen Eindruck zu gewinnen, betrachten wir die Abb. 1 und 2, Taf. III, die in einem Intervall von 48 Stunden, und zwar am 31.V. (1) und 29. V. (2) aufgenommen wurden. Abb. 1 beginnt mit einer 5 schlägigen tachykarden Gruppe, auf die eine 2 gliedrige bradyk., dann wieder eine 5 schlägige tachyk., abermals eine 2 gliedrige bradyk. und noch eine 5schlägige tachyk. Gruppe folgt. Von der dritten bradyk. Periode ist nur der erste Schlag sichtbar. Abb. 2 ent. hält in zwei aneinanderzufügenden Teilen ( $(\mathrm{a}$ und $\mathrm{b}$ ) je 3 volle 14 schlägige tachyk. und drei 2 schlägige bradyk. Perioden.

Aus diesen beiden Abbildungen kann unmittelbar die für alle weiteren Untersuchungen wichtige Folgerung abgeleitet werden, daß die vorliegende Periodenbildung von den basalen supraventrikulären Herzabschnitten ausgehen muß. Denn nur so ist es möglich, daß die Kammerkomplexe beider Gruppen formgleich sind und in ungefähr gleichem Abstande von den ihnen vorangehenden P-Zacken stehen. Die weiteren Elemente, die zur Analyse der zu untersuchenden, allem Anscheme nach an ein festes Gesetz gebundenen Allorhythmie dienen könnten, sind die aus den elektrographischen Kurven zu entnehmenden zahlenmäßigen Beziehungen zwischen den einzelnen Gruppen und den sie zusammensetzenden Gliedern. Das zu diesem Zwecke erforderliche große Material kann natürlich nicht in Form von Abbildungen geboten werden. Ich habe es deshalb in Tabellen zusammengefaßt, die im wesentlichen die Dauer der Vorhofperioden, auf die es ja vor allem ankommt, wiedergeben. Um auch die Gruppenbildung hervortreten zu lassen, sind die Reizperioden, d. h. die Abstände der P-Zacken der in den Abb. 1 und 2 durch ihre Länge sofort ins Auge fallenden Schläge von den übrigen entsprechend abgegrenzt.

In dieser Weise gibt Tab. I einen Úberblick über den periodischen Rhythmus an 7 verschiedenen Tagen. Von je drei zusammengehörigen Stäben enthält der erste die aufeinanderfolgenden Vorhofperioden in Hundertelsekunden. Im zweiten Stabe ist die Dauer der ganzen tachyk. Periode (Mittelwert) als Zähler, die Anzahl der die tachyk. Gruppen bildenden Glieder als Nenner eingetragen, woraus sich die ebenfalls beigefügte mittlere Periodendauer der tachyk. Gruppen als Quotient ergibt. Die den Abbildungen entsprechenden Teile der Tabelle enthalten einen betreffenden Hinweis. Wegen der unregelmäßigen Bewegung der Schreibfläche ist bei eventueller Nachmessung der Kurven stets die Projektion auf die Zeitabszisse notwendig. Trotz der dadurch 
bedingten Ungenauigkeit und trotz des Umstandes, daß in den Originalvorlagen die Zeit in Einheiten von 0,2 Sek. geschrieben, in den Tabellen aber in solchen von 0,01 Sek. ausgedrückt ist, sind die begangenen stets Meßfehler verhältnismäßig gering. Sie betragen, wie ich mich durch Addition der einzelnen Schätzwerte und Ausmessung des ganzen ihrer Summe entsprechenden Kurvenstückes wiederholt überzeugt habe, selbst für längere 10-20 Glieder zählende Gruppen selten mehr als $0,05-0,1$ Sek.

Zwischen den einzelnen Aufnahmen der Tab. I liegen Intervalle bis zu 2 Monaten. Trotzdem bleibt die Art der Herztätigkeit im Grunde unverändert. Immer folgen auf eine Gruppe abnorm rascher Schläge 2-3 langsame. Innerhalb dieses stets gleichen Rahmens verändert sich nur die Gliederzahl der Gruppen und die Dauer der Reizperioden. Aber auch diese können in langen, aufeinanderfolgenden Reihen einen fast vollkommen gleichmäßigen Bau aufweisen. In Tab. I kommt die große Regelmäßigkeit der Allorhythmie nur in den 3 letzten Stäben genügend zum Ausdruck, da absichtlich auch kleinere und größere Abweichungen in die Tabelle aufgenommen wurden.

Die Gruppenschlagzahl weist in Tab. I an gleichen Tagen mit Ausnahme von Kolonne 4, wo hintereinander eine 19- und 38 gliedrige tachyk. Gruppe erscheint, nur geringe Schwankungen auf. Aber auch zu verschiedenen Zeiten ist allein die Zahl der die tachyk. Gruppen bildenden Glieder stärker veränderlich. Die Extreme liegen in Tab. I zwischen 5 und 38 Gliedern. Demgegenüber bestehen die bradyk. Perioden immer aus wenigen, meist $2-3$ Schlägen.

Die Dauer der Reizperioden ist innerhalb einer Gruppe nicht ganz regelmäßig. Die Differenz zwischen dem kürzesten und längsten Schlage erreicht jedoch in den tachyk. Gruppen nur selten 0,1 Sek. und beträgt gewöhnlich nicht mehr als 0,05 Sek. Die größeren Unterschiede in Kolonne 3 und 4 von Tab. I sind Ausnahmen, die wie auch andere stärkere Abweichungen in die Beispiele der Tab. I aufgenommen wurden, um möglichst viele Variationen darzustellen. In den bradyk. Gruppen sind die Abweichungen etwas größer. An gleichen Tagen sind die Durchschnittswerte der Reizperiodendauer in den tachyk. Gruppen fast konstant. Es gleichen sich nämlich die in den einzelnen Gruppen vorkommenden Unregelmäßigkeiten fast vollkommen aus. Dieser Ausgleich geht so weit, daß sich als Gesetz ergibt, daß gleich sch lägige tachyk. Gruppen von gleicher Dauer sind. Wir finden z. B. am 4. XII. 5 fünfgliedrige tachyk. Gruppen von $2,46,2,48,2,44,2,48$ und 2,46 Sek., 2 sechsgliedrige von 2,95 und 2,96 Sek., sowie 3 achtgliedrige von 3,92, 3,94 und 3,95 Sek. Aus den vielen anderen in Tab. I hierfür vorhandenen Belegen hebe ich nur noch die 3 vierzehnschlägigen Gruppen vom 29. V. Kolonne 6 (Abb. 2) hervor, die 7,45, 7,45 und 7,44 
Sek. messen. Dagegen ist die durchschnittliche Reizperiodendauer der bradyk. Gruppen auch an gleichen Tagen nicht selten etwas größeren Schwankungen unterworfen. Sie kann aber ebenfalls fast absolut konstant bleiben und wir finden dann auch gleichlange bradyk. Gruppen wie z. B. in Abb. 2 (Tab. I, Kolonne 6), wo die 3 ersten bradyk. Gruppen eine Dauer von 2,76, 2,77 und 2,78 Sek. besitzen. Es ist wohl klar, daß nur durch einen ganz gesetzmäßigen Vorgang diese Gleichheit der Gruppenbildung bedingt sein kann. Wenn also die bradyk. Gruppen in ihrer Dauer öfter und stärker voneinander abweichen, so kann der Grund dafür nur darin liegen, daß die bradyk. Schläge durch Störungen, die von dem eigentlichen, das Gesetz diktierenden Mechanismus abseits liegen, leichter beeinflußbar sind, als die tachyk. Schläge.

Vergleicht man die Dauer der einzelnen Perioden und ihrer Mittelwerte an verschiedenen Tagen, so ergeben sich natürlich größere Divergenzen, die ebenfalls vor allem die bradyk. Schläge betreffen. Für die einzelnen tachyk. Perioden liegen die Grenzwerte in Tab. I, abgesehen von der in der 38 schlägigen Gruppe vom 16. II. enthaltenen ganz isolierten Vorhofperiode von 0,65 Sek., zwischen 0,46 und 0,6 Sek., für die Mittelwerte der tachyk. Gruppen jedoch nur zwischen 0,49 und 0,54 Sek. Die Dauer der bradyk. Perióden bewegt sich zwischen 0,84 und 1,44 Sek., die ihrer Mittelwerte zwischen 0,88 und 1,39 Sek. Berechnet man aus diesen Mittelwerten die Minutenfrequenz, so würden für die bradyk. Perioden 43-68, für die tachyk. Perioden 111-122 Schläge resultieren.

Zur Beurteilung des Verhältnisses der durchschnittlichen Dauer der tachyk. und bradyk. Gruppen steht in Tab. I nur das kleine Material aus 7 Tagen zur Verfügung. Es genügt auch tatsächlich nicht, um zu erkennen, daß sich die Frequenz der tachyk. und bradyk. Perioden im großen ganzen gleichsinnig ändert, und zeigt nur, daß dieser Zusammenhang keineswegs so enge ist, daß zu einer bestimmten mittleren bradyk. Periode eine ebenso bestimmte mittlere tachyk. Periode gehören würde. Zu beachten ist dabei, daß die Zahl der tachyk. Glieder für ihren Mittelwert ziemlich gleichgültig ist, daß dagegen die bradyk. Perioden im Durchschnitt kürzer werden, wenn ihre Zahl zunimmt. Es verhält sich z. B. der Mittelwert der bradyk. Perioden zu dem der tachyk. am 19. I. wie 111 zu 53 und am 29. V. wie $136 \mathrm{zu} 53$, dafür bestehen aber die bradyk. Gruppen am 19. I. aus 3, am 29. V. nur aus 2 Schlägen.

Der Ba u der tachyk. Gruppe. Die einzelnen tachyk. Gruppen sind, wie schon erwähnt wurde, aus Gliedern von ungleicher Länge, die aber gewöhnlich nicht weit vom Mittelwert abweichen, zusammengesetzt. Eine, wenn auch nicht durchgreifende GesetzmäBigkeit besteht insofern, als in der überwiegenden Mehrzahl das erste Glied 


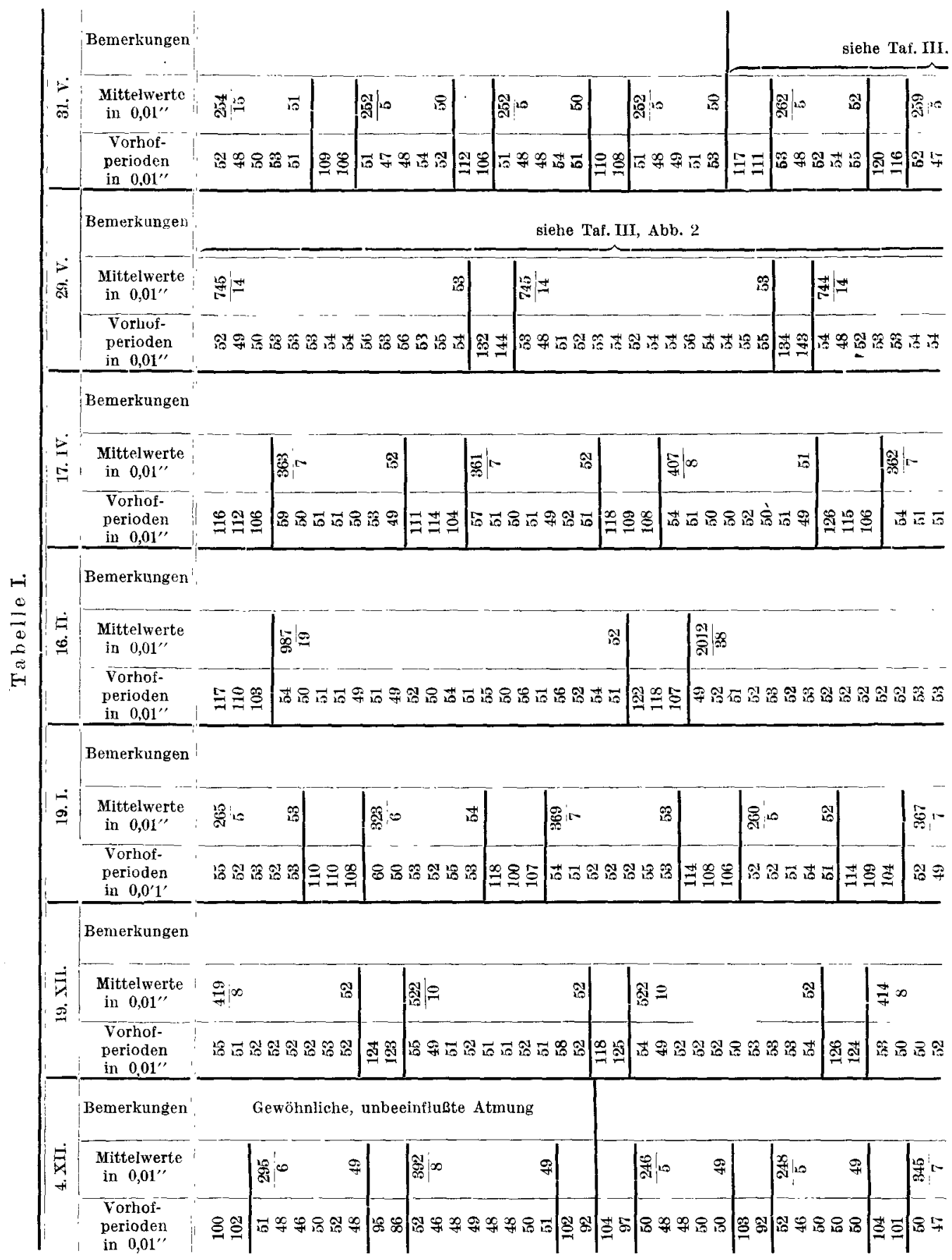




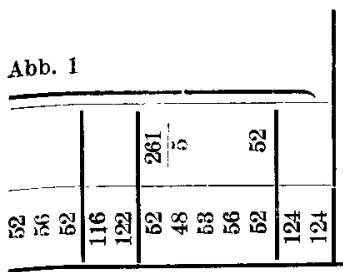
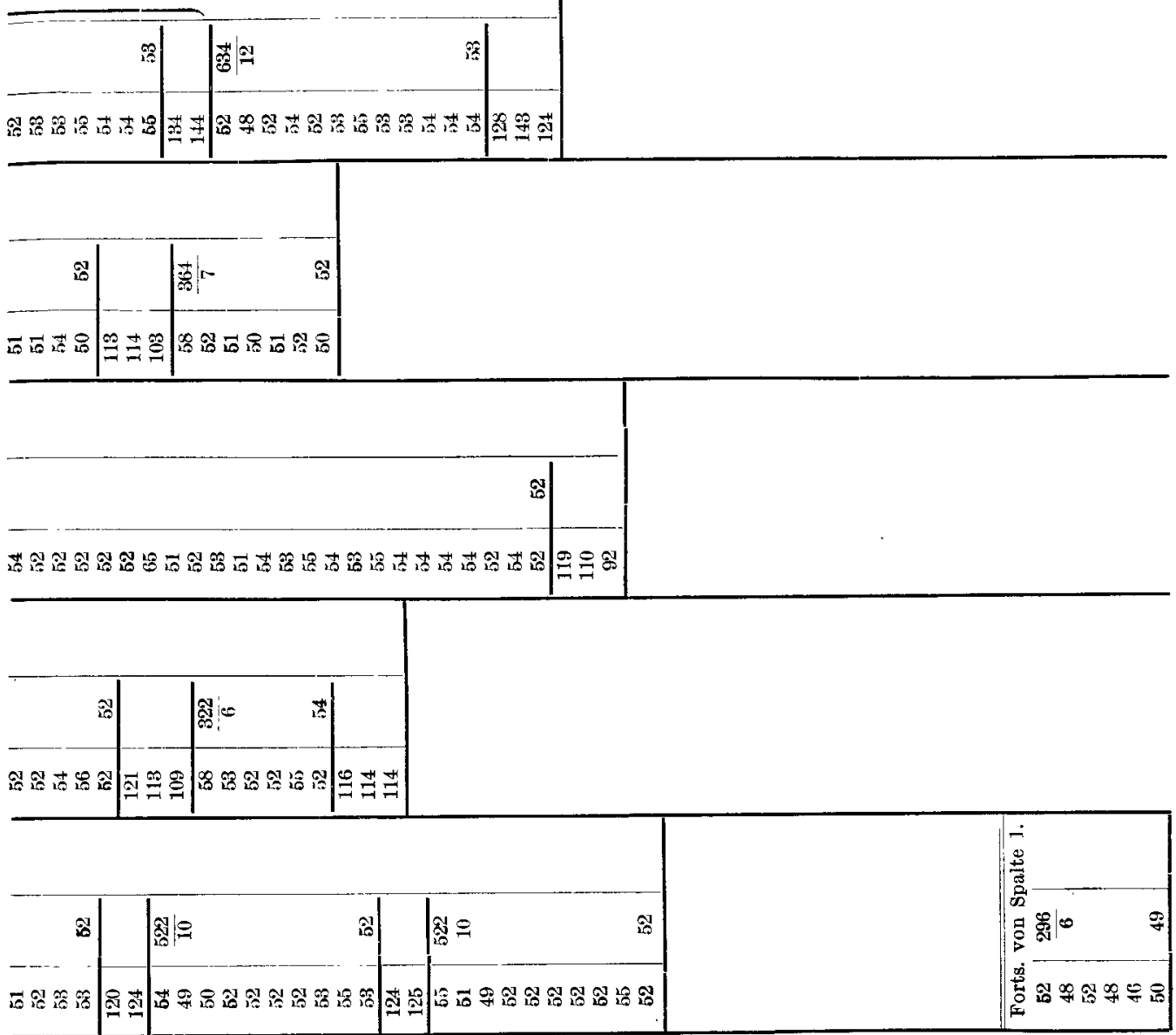

Tiefe, langsame Atmung

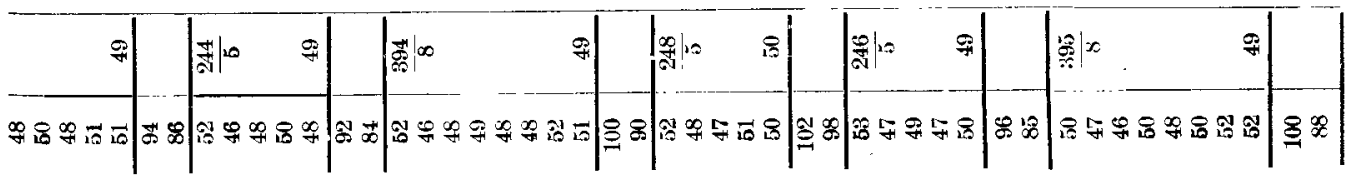


eines der längsten, das zweite, manchmal auch das dritte Glied das kürzeste der ganzen Gruppe ist. Nicht selten hat dann auch das KammerEkg. des zweiten Gliedes eine etwas abweichende Form. Diese Veränderung, die wegen des supraventrikulären Ursprunges der Periodik nur sekundäre Bedeutung beanspruchen kann, besteht darin, daß $R$ und $S$ niedriger sind und $S$ manchmal im aufsteigenden Schenkel eine Knotung trägt (Taf. III, Abb. 1 u. $R_{10}$ in Taf. IV, Abb. 6). Im übrigen sind die Frequenzchwankungen innerhalb einer Gruppe, wie früher erwähnt, unregelmäßig, insbesondere läßt sich ein allmähliches Anwachsen und Wiederabnehmen der Schlagzahl nicht nachweisen.

In den bradyk. Gruppen ist meist der erste Schlag der längste und, wenn die Gruppe aus 3 Schlägen besteht, der dritte am kürzesten. Doch sind die Ausnahmen hiervon zahlreich, insbesondere kann die zweite, seltener die dritte Periode die längste sein. Beispiele hierfür sind leicht in den beigegebenen Tabellen und Abbildungen aufzufinden.

\section{Analyse der Periodik.}

Bei dem Versuche einer Analyse der vorliegenden periodischen Tätigkeit des Herzens haben wir, wie schon eingangs erwähnt, mit folgenden Möglichkeiten zu rechnen: 1. der respiratorischen Arhythmie, 2. dem periodischen Systolenausfall, 3. regelmäßig wiederkehrenden extrasystolischen Reihen und endlich 4. mit Lucianischen Perioden. Die aus der bloßen Anschauung der elektrographischen Kurven gewonnene Erkenntnis, daß es sich um eine supraventrikuläre Störung handeln muß, läßt alle die genannten Möglichkeiten offen.

Der Annahme einer respiratorischen Arhyth mie widersprechen jedoch schon die in Tab. I dargestellten Verhältnisse. In Kolonne I sind zwei Kurvenstücke tabelliert, von denen das erste bei gewöhnlicher, das zweite bei willkürlich vertiefter und verlangsamter Atmung geschrieben wurde. Trotzdem ist in beiden Fällen die Periodik ziemlich gleich. In allen übrigen Stäben von Tab. I wurde auf die Respiration kein Einfluß genommen und dennoch kommen in der Gruppenbildung die größten Abweichungen vor. Bei gleichzeitiger Verzeichnung der Atembewegungen und des Ekg, traf es sich allerdings manchmal, daß die bradyk. Gruppen mit der Atmungspause zusammenfielen. Durch Verfolgung längerer Kurvenstücke ließ sich aber immer die unregelmäßige Projektion der einzelnen Gruppen auf die verschiedenen Atmungsphasen feststellen. In sehr anschaulicher Weise demonstriert Abb. 3, Taf. III, ihre Unabhängigkeit voneinander, indem einmal eine tachyk. und gleich darauf eine bradyk. Gruppe die gleichen Atmungsakte ausfüllen.

Vorhofsystolenausfall. Als weitere Eventualität ist der Ausfall von Vorhofsystolen (Sinusblock) als Ursache der bradyk. Perioden in Betracht zu ziehen. Tatsächlich kamen bei unserem Patienten sicher 
nachweisbare Störungen der Reizübertragung von den Vorhöfen auf die Kammern (Vorhofblock) vor. Sie fanden sich nur in den tachyk. Gruppen, innerhalb welcher die Utberleitungszeit fast immer merklich länger ist, als bei den bradyk. Schlägen. So ist z. B. in Taf. III, Abb. 1 das Intervall $\mathbf{P}_{\mathbf{8}}-\mathbf{R}_{8}$ deutlich kürzer als $\mathbf{P}_{9}-\mathbf{R}_{\mathbf{9}}$. Obwohl dieses Wachsen der tberleitungszeit schon auf ein gewisses Mißverhältnis von Schlagfrequenz und Leitfähigkeit in den tachyk. Gruppen hinweist, wurden $\mathrm{V}_{s}$-Ausfälle gewöhnlich doch nur bei Vagusdruck und unter dem Einflusse von Digitalis beobachtet. Hier waren sie dann allerdings sehr häufig. Ausnahmsweise erscheinen sie aber auch spontan, wie z. B. in Taf. III, Abb.4 vom 19. IV. Das P-R-Intervall wächst hier anfangs langsam, von $P_{9}$ jedoch rasch an. $P_{11}-R_{11}$ hat bereits eine Dauer von wenigstens $0,3 \mathrm{Sek}$. (Eine genaue Messung läßt sich wegen der teilweisen Superposition von $T$ und $P$ nicht ausführen.) $P_{12}$ fällt dadurch in die noch nicht abgelaufene, vorangehende $V_{s}\left(T_{11}\right)$ und wird blockiert. $\mathrm{V}_{s-12}\left(\mathrm{R}_{12}+\mathrm{T}_{12}\right)$ bleibt aus, es folgt aber noch die Schlußperiode der tachyk. Gruppe und dann erst setzt die bradyk. Gruppe ein. Sie besteht aus 3 Gliedern von ungewöhnlich langer Dauer (Mittel = 1,43 Sek.), denen auch durchschnittlich längere (0,54 Sek.) tachyk. Perioden entsprechen. Wodurch die langsamere Frequenz in beiden Gruppen und die gelegentlichen $\mathrm{V}_{s}$-Ausfälle an diesem Tage bedingt waren, ist nicht klar. Der Patient war 8 Tage früher von einem längeren Urlaube zurückgekehrt, erhielt seither kein Medikament, und die elektrographische Aufnahme am Tage vorher (18. IV., s. Tab. VI) hatte noch die gewöhnlichen Verhältnisse ergeben.

Es fragt sich nun, ob auch die bradyk. Perioden durch Systolenausfall hervorgerufen sind. Da während derselben in den verschiedenen Ableitungen keine Zeichen von Vorhofstätigkeit sichtbar sind, könnten sie nur durch sino-aurikuläre Blockierung entstanden sein. In diesem Falle wäre zu erwarten, daß die bradyk. Perioden einem ganzen Vielfachen der tachyk. Schläge gleichkämen. In Tab. I gibt es nun tatsächlich viele Beispiele, wo die Pulse der bradyk. Gruppen annähernd, bisweilen sogar genau die doppelte Dauer der angrenzenden tachyk. Perioden haben. Utber kleine Differenzen könnte man um so eher hinwegsehèn, als ja die Schlagfolge innerhalb der tachyk. Gruppen nicht ganz regelmäßig ist. Auch wäre daran zu denken, daß die Blockierung mit einer wegen des Fehlens der P-Zacken nicht direkt nachweisbaren Pulsverlangsamung - z. B. durch periodische Erhöhung des Vagustonus - verbunden sei und daß darum di ebradyk. Perioden meist etwas länger wären als die zweifachen tachyk. Pulse. So ließen sich z. B. die Gruppenbildungen am 4. XII., 19. I. und 16. II. durch Vorhofsystolenausfall zur Not erklären. Manchmal aber, insbesondere am 19. XII. sind die Differenzen dazu schon viel zu groß, und am 29. V. 
sowie in der eben herangezogenen Abb. 4 vom 19. IV. nähern sich sogar die bradyk. Perioden schon dem dreifachen Werte der angrenzenden tachykardischen. Man müßte also in ganz willkürlicher Weise annehmen, daß hier je 2 Erregungen nacheinander vom Vorhof abgeblendet würden und sich überdies damit zufrieden geben, daß diesmal die bradyk. Perioden nicht länger, sondern um etwas kürzer wären als das dreifache Multiplum der tachyk. Pulse.

Es ist daher die Erklärung der Gruppenbildung durch Vorhofsystolenausfälle unhaltbar, sobald man von der Voraussetzung ausgeht, daß bei bestehender Sinustachykardie die nomotopen Erregungen rhythmisch an der Sinus-Vorhofgrenze gesperrt werden.

Eine andere Auffassung, bei der man an der Entstehung der bradyk. Gruppen durch Vorhofsystolenausfall festhalten könnte, ohne darum eine Übereinstimmung der einzelnen bradyk. Perioden mit einem ganzen Vielfachen der bradyk. Schläge fordern zu müssen, bestünde darin, daß im Sinne von Kaufmann und Rothberger ${ }^{1}$ ) ebenfalls eine fortlaufende aber heterotope Vorhoftachysystolie angenommen würde, bei der die Erregungen periodisch vollständig blockiert werden, so daß inzwischen die normalen Sinusreize zur Geltung kämen. In diesem Falle wäre also die Herztätigkeit nicht mehr unifokal, sondern es würden zwei Reizbildungsstellen in regelmäßiger Weise miteinander interferieren. Die Besprechung dieses komplizierten Vorganges wäre wegen der ihm zugrunde liegenden heterotopen Vorhofsautomatie eigentlich erst in den folgenden Kapiteln am Platze. Doch können wir immerhin die Heterotopie der tachyk. Ursprungsreize vorläufig voraussetzen und untersuchen, ob dann auch wirklich die übrigen Erscheinungen durch zeitweise Abblendung der heterotopen Reize, also ebenfalls durch Vorhofsystolenausfall erklärt werden. Lassen wir uns auf diese Prüfung ein, so ist zu beachten, daß zwar die einzelnen bradyk. Perioden in keiner gesetzmäßigen Beziehung zu den tachyk. Pulsen stehen werden, daß aber die Länge der ganzen bradyk. Gruppe ein Vielfaches der tachyk. Perioden sein müßte, da ja in die durch Blockierung der tachysystolischen Reize entstandene Lücke die bradyk. Gruppe gleichsam eingepaßt wäre. Wir haben demnach den bradyk. Pulsen noch die erste tachyk. Periode, die ja auch vom Sinus ausgehen und durch die einsetzenden heterotop automatischen Schläge verkürzt sein könnte, hinzuzufügen und die Summe durch den Mittelwert der tachyk. Perioden zu teilen. Daß sich auf diese Weise sehr leicht eine annähernde Deckung der bradyk. Gruppen mit einem Multiplum der tachyk. Perioden ergeben kann, ist um so wahrscheinlicher, je größer der Wert ist, den die bradyk. Gruppe gegenüber der einzelnen tachyk. Periode

1) Kaufmann und Rothberger, Beiträge zur Entstehungsweise extrasystolischer Allorhythmien. Zeitschr. f. d. ges. experim. Med. y, 199. 1919. 
d. i. gegenüber ihrem Teiler repräsentiert. Mißt z. B. die ganze bradyk. Gruppe 300 und die tachyk. Periode 50 Einheiten, so wird die Abweichung der Gruppe vom ganzen Vielfachen maximal $\pm 0,25$ Sek. betràgen können. Daher ist bei der Beurteilung großeVorsicht geboten. Nur wenn die Differenzen sich konstant von dem möglichen Fehler weit entfernt hielten, wäre das ein Beweis für die gemachte Annahme. In Tab. II habe ich nun diese Berechnung für die in Tab. I enthaltenen Werte durchgeführt. In den einzelnen Stäben der Tab. II ist eingetragen 1. die Summe der bradyk. Perioden + der ersten tachyk. Periode, 2. das dieser Summe nächstliegende aus dem Durchschnitt der vorangegangenen tachyk. Gruppe gebildete Multiplum. (Nur für den 16. II. ist der Mittelwert der nachfolgenden tachyk. Gruppe gewählt.) 3. Die Differenz dieser beiden Zahlen.

Demnach resultiert in 33 Bestimmungen 6 mal ein Fehler von $+0,020,08$ Sek., 18 mal ein Fehler von t $0,09-0,18$ Sek. und 9 mal ein Fehler von $\pm 0,19$ bis 0,24 Sek. Dieses Verhältnis entspricht mit Rücksicht auf die kleine Beobachtungsreihe so ziemlich derWahrscheinlichkeit, nach der die kleinsten und größten Abweichungen am seltensten, die mittleren am häufigsten zu erwarten sind.

Es ist also nicht gelungen, die Interferenz zweier Reizbildungs-

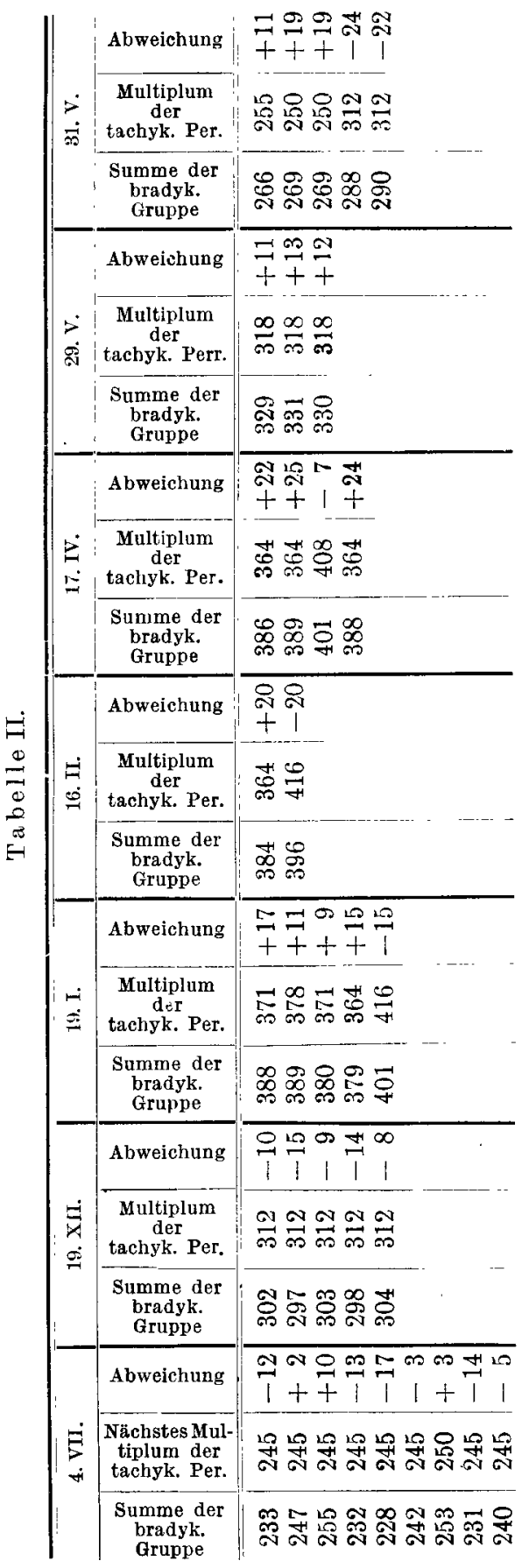


punkte in dem angenommenen Sinne zu beweisen, ebensowenig aber sie dadurch zu widerlegen. Denn es besteht noch die Möglichkeit, daß die heterotope automatische Rhythmik während der Pausen zwar fortbesteht, aber durch die nomotopen Erregungswellen gestört wird. Darauf näher einzugehen, würde jedoch an dieser Stelle zu weit führen. Gilt es doch erst einmal darüber Klarheit zu gewinnen, ob überhaupt von bifokaler Reizbildung weiter die Rede sein kann.

Extrasystolische Reihen und Lucianische Perioden.

Als Ursache periodischer Herztätigkeit kommen noch zwei Möglichkeiten in Betracht, nämlich periodisch auftretende Reihen aurikulärer Extrasystolen und die sog. Lucianischen Perioden. Die Extrasystolen wiederum könnten nomotope oder heterotope sein. Bei nomotopem Ursprunge wären sie von Lucianischen Perioden nur noch schwer zu trennen. Denn diese sind im Sinne ihres Entdeckers ${ }^{1}$ ), ,auf Veränderungen des reizenden Apparates" oder in moderner Sprache ,auf rhythmische Schwankungen der automatischen Tätigkeit des Schrittmachers des Herzens": [Wenckebach'2)] zu beziehen, ein Vorgang, der mit dem, was wir uns unter einer periodischen nomotopen Polygeminie vorzustellen haben, ziemlich identisch wäre.

Auf Grund dieser Überlegung vereinfacht sich unsere Fragestellung dahin, ob die bradyk. und tachyk. Gruppen im Sinusknoten entstehen, oder ob die einen, eventuell auch die anderen einen abnormen Reizursprung besitzen. Bei bloßer Betrachtung der in den Abbildungen dargestellten Periodik sind vielleicht viele geneigt, die tachyk. Schläge a priori als Gruppen aurikulärer Extrasystolen anzusehen. Verlangt man aber Beweise für diese Annahme, so ergeben sich sofort Schwierigkeiten. Im Tierexperimente besitzen wir in der Bestimmung der ,ersten Negativität" bei direkter Ableitung von verschiedenen Punkten der Herzoberfläche ${ }^{3}$ ) ein Mittel zur Bestimmung des Ausgangspunktes einer Herzkontraktion. In der Klinik gibt uns nur die Form der Vorhofschwankung im Ekg. und die Länge der Überleitungszeit einigermaßen brauchbare Anhaltspunkte. Bei den vom Sinusknoten ausgehenden Erregungen ist die P-Zacke gewöhnlich in allen Ableitungen positiv, in Abl. I klein, oft kaum wahrnehmbar, in Abl. II am größten. Kleine Gestaltveränderungen besagen nicht viel, können aber an Bedeutung gewinnen, wenn sie mit anderen, auch nicht weit abweichenden Formen in derselben Kurve vorkommen und besonders dann, wenn sie sich mit

1) Luigi Luciani, Eine periodische Funktion des Froschherzens. Arbeit. aus der phys. Anstalt zu Leipzig. VII. Jahrg. 1872. S. 113.

2) Wenckebach, Die unregelmäßige Herztätigkeit und ihre klinische Bedeutung. Leipzig-Berlin 1914. S. 196.

3) Eyster und Meek, Experiments on the origin and progapation of the impulse in the heart. Heart 5, 119. 1914. 
einer konstanten Veränderung der Ủberleitungszeit verbinden. In unseren Abbildungen läßt sich nun tatsächlich zwischen den P-Zacken der bradyk. und tachyk. Gruppen ein in den meisten Fällen allerdings kaum merklicher Unterschied auffinden, der darin besteht, daß P während der Beschleunigungsgruppen etwas niedriger und flacher erscheint. Am deutlichsten ist diese Formverschiedenheit in Taf. V, Abb. 11 vom 21. I. nach Adrenalininjektion ausgeprägt. Obwohl hier, wie auch sonst in den tachyk. Gruppen, eine mehr oder weniger deutliche Verlängerung des Intervalles $\mathrm{P}-\mathrm{R}$ hinzukommt, wäre es doch zu gewagt, daraus allein auf eine Verschiedenheit der Reizbildungsstellen in den bradyk. und tachyk. Gruppen zu schließen. Denn die geringe Deformation von $\mathbf{P}$ während der tachyk. Gruppen könnte vielleicht auch durch das nahe Heranrücken von $P$ an $T$, das bis zu einer teilweisen Verschmelzung von $\mathrm{P}$ und $\mathrm{T}$ führen kann, bedingt sein; ebenso könnte die etwas längere Úberleitungszeit mit der rascheren Schlagfolge bzw. mit der Verkürzung der Diastole zusammenhängen. Stärkere Veränderungen von P.kommen dagegen bisweilen in den bradyk. Gruppen vor. Hier ist manchmal die eine oder die andere Vorhofschwankung in eine sehr niedrige aber zweigipfelige Erhebung umgewandelt wie z. B. in Taf. V, Abb. 15 vom 7. XII. oder es tritt an Stelle von $P$ ein kaum noch wahrnehmbarer Ausschlag wie in Taf. III, Abb. 3 vom 13. IV. oder in Taf. IV, Abb. 7 vom 29. V. Aber auch daraus geht höchstens hervor, daß während der verlangsamten Herztätigkeit verschiedene Reizbildungsstellen miteinander interferieren können. Die Periodik selbst ist damit nicht zu erklären.

Sehr wichtig für die Auffassung der tachyk. Gruppen als extrasystolische Reihen wäre das Auftreten einer ihnen folgenden kompensatorischen Ruhe. Tatsächlich ist im allgemeinen die erste bradyk. Periode die längste ihrer Gruppe. Um Vaguswirkung kann es sich dabei nicht gut handeln. Vom Tempo der Atmungsbewegungen, also auch von den von da aus zufließenden Erregungen sind die Gruppen unabhängig. Für die übrigen Reflexe aber dürfte, ob sie nun in der Bahn der Hemmungs- oder Förderungsnerven ablaufen, gerade eine gewisse, ihren Entstehungsbedingungen entsprechende Unregelmäßigkeit charakteristisch sein. Es ist deshalb nicht unwahrscheinlich, daß die erste bradyk. Periode die kompensatorische Pause in sich schließt und darum gewöhnlich länger ist als die übrigen. Trotzdem bleibt eine gewisse Unsicherheit bestehen; denn nicht allzu selten übertrifft die zweite und ausnahmsweise sogar die dritte bradyk. Periode die übrigen an Dauer.

Da sich also weder durch das Verhalten der P-Zacken im Ekg., noch durch den sicheren Nachweis einer kompensatorischen Ruhe die aufgeworfene Frage lösen ließ, versuchte ich durch verschiedene Eingriffe differente Wirkungen auf beide Perioden hervorzurufen, um vielleicht so ihre verschiedene Entstehungsweise klarzulegen. 
Solche Versuche mußten übrigens schon deshalb von Interesse sein, weil über den Einfluß von Nervenerregungen oder toxischen Agentien auf extrasystolische bzw. automatische Reihen fast nichts bekannt ist.

\section{Vagusdruckversuche.}

Als einfachstes Mittel bediente ich mich zunächst der Vagusreizung durch Druck auf den Halsvagus, manchmal auch durch Druck auf die Bulbi. Ich ging dabei von der Vorstellung aus, daß die Vagi auf die einzẹlnen, in den Vorhöfen gelegenen Reizbildungsstellen nicht dieselbe Wirkung haben müßten. Unsere Kenntnisse sind in dieser Beziehung allerdings noch sehr ergänzungsbedürftig. Sichergestellt ist, daß die Vagi am Sinus- und Atrioventrikularknoten angreifen. Dagegen ist die Beeinflussung der sog. tertiären Zentren immer noch fraglich. Hinsichtlich der Kammern liegen differente Angaben vor. Da ich in Fällen von totaler Dissoziation beim Menschen nur dann durch Vagusdruck eine deutliche Verlangsamung der Kammertätigkeit erzielen konnte, wenn die Kammerfrequenz relativ hoch und das Kammer-Ekg. annähernd normal war, glaube ich, daß eine chronotrope Hemmung der automatisch schlagenden Kammern gewöhnlich nur dann erfolgt, wenn die reizbildende Stelle noch im Bereich des Tawaraknotens liegt. Ähnlich könnten die Verhältnisse in den Vorhöfen sein. Daß der Sinusknoten und die oberen den Vorhöfen angehörenden Teile des Tawaraknotens vom Vagus beherrscht werden, steht fest [Rothberger und Winterbe ${ }^{1}{ }^{1}$ ), Ganter und $\left.\mathrm{Zahn}^{2}\right)$ ]. Gewiß gibt es aber in den Vorhöfen auch andere, sogar hochfrequente Reize erzeugende Punkte, welche die Vagi nicht zu hemmen vermögen. So konnte ich in einem Falle von regelmäßigem Vorhofflattern mit einer durch viele Monate stets gleichen Flatterfrequenz von 263-270 Schlägen pro Minute diese durch Vagusdruck nicht im geringsten verlangsamen, obwohl die dromotope Wirkung gleichzeitig so stark war, daß die Kammern bis zu 7 Sek. vollständig stillgestellt wurden. Als es aber durch energische Digitalis-Chininbehandlung geglückt war, das Flattern zu beseitigen, wurden durch Vagusdruck auch die Vorhöfe ebenso lange zur Ruhe gebracht. Es war daher außer Zweifel, daß durch den Vagus der Sinusknoten, nicht aber die das Flattern provozierende Reizbildungsstelle beeinflußt wurde. Auch in unserem Falle von Periodenbildung wäre ein verschiedenes Verhalten beider Gruppen gegenüber der Vaguserregung von Bedeutung. Glücklicherweise war der Vagusdruck bei dem Patienten sehr wirksam; doch benötigte man zur Erzielung eines guten Effektes immer eines ziemlich

1) Roth berger und W in t er berg. Utber die Beziehungen der Herznerven zur atrioventrikulären Automatie. Pflügers Arch. 135, 559. 1910.

$\left.{ }^{2}\right)$ Ganter und Zahn. Uber die Beziehungen der Nn. Vagi zu Sinusknoten und Atrioventrikularknoten. Pflügers Arch. 154. 1913. 
kräftigen, die anliegende Carotis sicher komprimierenden Druckes. Durch gleichzeitige Auscultation des Herzens war es leicht, den Druck im Beginne einer bradyk. oder tachyk. Gruppe oder in einem anderen, beliebigen Momente auszuüben. Für Tab. III sind nur einige der überaus zahlreichen Vagusdruckversuche ausgewählt worden. Zur näheren Illustration dienen die Abb. 5-10 auf Taf. IV.

Die Beeinflussung der bradyk. Perioden durch Vagusdruck geht aus Tab. III, in der allerdings vorzugsweise stärkere Effekte gesammelt sind, überaus deutlich hervor. Die Wirkung besteht in einer mehr oder weniger ausgesprochenen weiteren Verlangsamung der einzelnen bradyk. Perioden und kann so intensiv werden, daß das Herz für mehrere Sekunden völlig stillgestellt wird. In Abb. 5 vom 29 . V. dauert der Herzstillstand bei Druck auf den rechten Vagus 3,65 Sek. Eine andere, viel seltenere Form des Vagusdruckeffektes ist in Abb. 6 vom 13.IV. (Tab.III, Stab 4) wiedergegeben. Auch hier ist die Wirkung sehr stark, besteht aber nicht so sehr in einer exzessiven Verlangsamung der einzelnen bradyk. Perioden, als vielmehr in einer Verlängerung der ganzen Gruppe durch Zunahme ihrer Glieder bzw. durch den Ausfall einer ganzen tachyk. Gruppe.

Die Beeinflussung der tachyk. Perioden durch Vagusdruck. Während innerhalb der bradyk. Gruppen negativ chronotrope Effekte jeden Grades durch Vagusdruck leicht erzielt werden können, ist eine chronotrope Hemmung der tachyk. Perioden nur in kleinem Umfange, ja oft überhaupt nicht hervorzurufen. An den einzelnen Gliedern der tachyk. Gruppen läßt sich die geringe, noch im Bereiche der auch sonst vorkommenden Frequenzschwankungen liegende Verlangsa mung oft kaum nachweisen. Sie kommt jedoch zum Vorschein, wenn die Mittelwerte der tachyk. Gruppen mit und ohne gleichzeitigen Vagusdruck verglichen werden. Man findet dann (Tab. III) unter manchen negativen Versuchen auch solche, bei denen unbedeutende, meist nur 0,01 Sek. betragende Verlängerungen des Durchschnittswertes feststellbar sind.

Gegenüber der schwachen chronotropen Hemmung ist es um so auffallender, daß durch Druck auf die Vagi die tachyk. Gruppen zeitweise völlig unterdrückt werden können. Diese Unterdrückung zeigen eigentlich schon die in den bradyk. Gruppen auslösbaren Stillstände an, die so lange dauern können (z. B. in Abb. 5 vom 29. V.), daß inzwischen längst die nächstfällige tachyk. Gruppe eingesetzt haben müßte, wenn ihr Eintritt durch Vaguserregung nicht verhindert worden wäre. Daß in Abb. 6 rom 13. IV. das dort beschriebene Anwachsen der bradyk. Gruppe auf 6 Glieder wahrscheinlich durch den Ausfall einer ganzen tachyk. Gruppe zustande gekommen ist, wurde bereits angedeutet. Ähnliches liegt vielleicht auch in den Versuchen vom 13. XII. und vom 29 . V. in Tab. III vor, wo nach Druck auf den rechten 


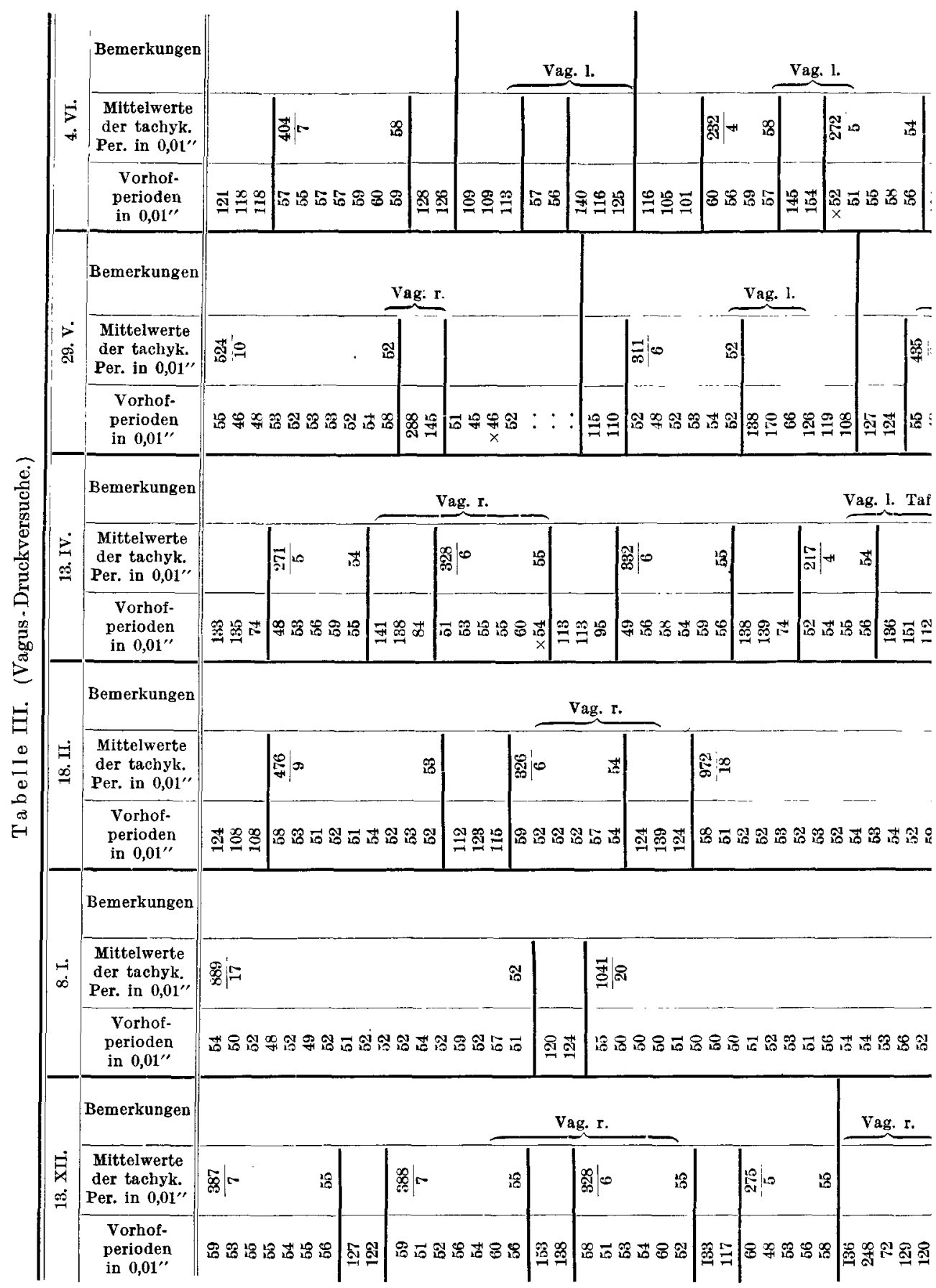


und Analyse der periodischen Herztätigkeit beim Menschen.

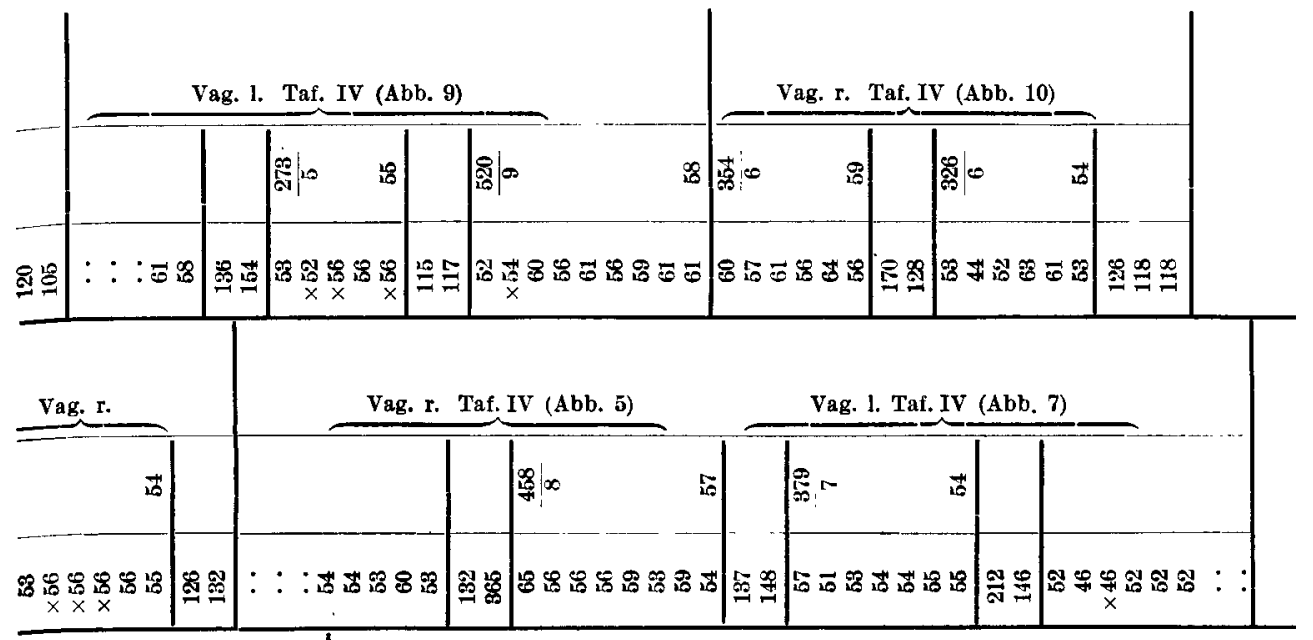

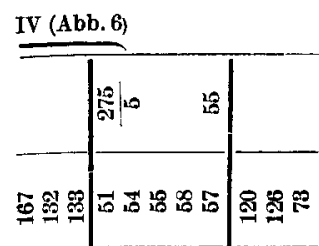
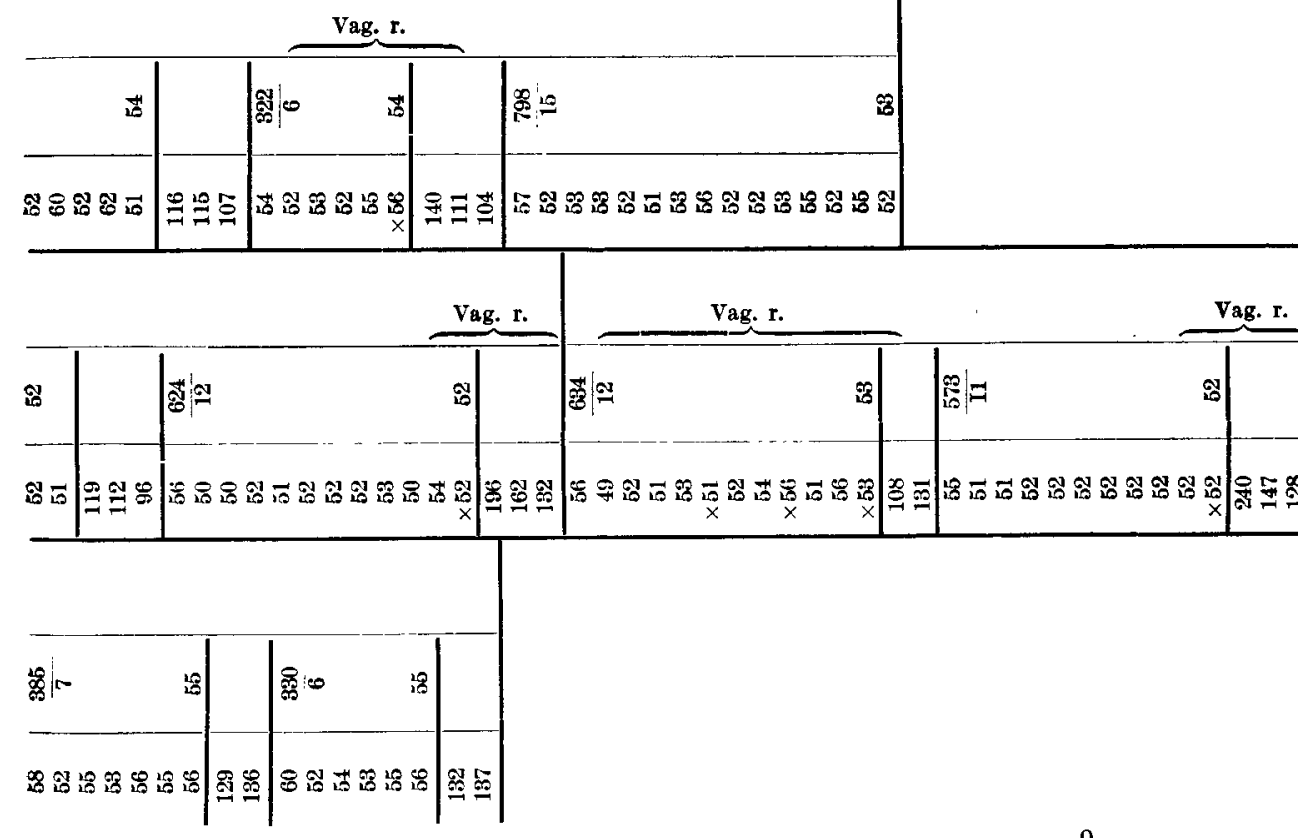
(13. XII.) bzw. linken Vagus (29. V.) die zu erwartende tachyk. Gruppe durch einen einzigen Schlag von 0,72 bzw. 0,66 Sek. Dauer ersetzt ist. Erfolgt die Druckerregung der Vagi nicht während der bradyk. sondern während der tachyk. Gruppe, so sieht man diese oft plötzlich und vorzeitig abreißen. Dadurch wird die Gliederzahl der tachyk. Gruppen mehr oder weniger stark reduziert. Am deutlichsten ist dieses Verhalten an solchen Tagen, an denen längere tachyk. Gruppen vorzukommen pflegen, wie z. B. in den Vagusdruckversuchen am 18. II. und 29. V. in Tab. III. Am 29. V. (Tab. I und II) finden sich meist ziemlich lange 10-14schlägige tachyk. Gruppen, während sie nach Vagusdruck schon nach 6-8 Gliedern abbrechen können, wie z. B. in Abb. 7, welche dem fünften Druckversuche in Tab. III entspricht. In der folgenden Abb. 8 vom 3. VI. wird durch Druck auf den rechten Vagus die eben beginnende tachyk. Gruppe auf 3 Vorhofschläge reduziert, von denen der dritte nicht mehr auf die Kammern übergeleitet wird. Auch in Abb. 7 endete die tachyk. Gruppe mit zwei $V_{s}$-Ausfällen.

Diese $V_{s}$-Ausfälle, eine sehr häufige Folge des Vagusdruckes während der tachyk. Gruppen, sind in den Tabellen durch beigesetzte Kreuze hervorgehoben. Sie können unter Umständen zu einer sehr beträchtlichen Pulsverlangsamung führen und eine starke chronotrope Wirkung des Vagusdruckes vortäuschen z. B. in Abb. 9 vom 4. VI. (Tab. III, Stab 6). Druck auf den linken Vagus (Abb: 9) verlängert sehr deutlich die bradyk. Perioden und erzengt auch in der folgenden tachyk. Gruppe durch den Ausfall von $3 \mathrm{~V}_{s}$ eine erhebliche Pulsverlangsamung, ohne indessen die an diesem Tage ungewöhnlich schwankende Frequenz der durch ihre P-Zacken kenntlichen Vorhofschläge wesentlich zu beeinflussen. Auch nach dem Aufhören des Vagusdruckes im Beginne der nächsten tachyk. Gruppe fällt noch eine $V_{s}$ aus.

Sehr oft führt der Vagusdruck nicht bis zu $V_{s}$-Ausfällen, sondern nur zu mehr oder weniger beträchtlichen Verzögerungen der Reizübertragung. Beispiele hierfür findet man in Abb. 5 und 7 vom 29.V., in Abb. 5 nach dem Aufhören des Vagusdruckes, in Abb. 7 am Ende desselben. Ebenso in Abb. 10 vom 4. VI., wo das Intervall P-R schließlich auf mindestens 0,3 Sek. anwächst und zur Superposition von $P$ auf $T$ führt. Auffallenderweise wird hier die Erregung trotzdem auf die Kammern übertragen, während in Abb. 7 bei der Superposition $V_{s}$-Ausfall erfolgt.

Die Störungen der Reizübertragung unter Vagusdruck kommen sowohl in Form des $V_{s}$-Ausfalles als auch in Gestalt einer verlängerten Übertragungszeit nur innerhalb der tachyk. Gruppen vor. Selbstverständlich haben sie mit der in erster Linie stehenden Frage nach der Vaguswirkung auf die Ursprungsreize der tachyk. Gruppen nichts zu tun und treten nur deshalb gerade hier zutage, weil die rasche Schlagfolge die Vorbedingungen zu ihrem Erscheinen schafft. 
Bricht nach einem $V_{s}$-Ausfall wie in Abb. 7 vom 29. V. und in Abb. 8 vom 3.VI. die tachyk. Gruppe ab, so könnte es vielleicht zweifelhaft sein, ob die folgende noch unter Vaguseinfluß stehende Vorhofperiode einem verlangsamten tachyk. oder brachyk. Pulse entspricht. Das Fehlen eines jeden Überganges und die Erfahrung, daß nach 2 oder 3 verlangsamten Schlägen ebenso unvermittelt wieder eine Beschleunigungsgruppe von annähernd gewöhnlicher Frequenz beginnt, spricht gegen die ersterwähnte Auffassung. Wegen der Schwierigkeit der Entscheidung, ob eine durch Vagusreizung verlängerte tachyk. Periode vorliegt, möchte ich aus Tab. III noch folgende Fälle hervorheben. Am 13. XII. die Periodenfolge 126, 248, 72, 129, 120, am 29. V. die ähnliche Gruppe 138, 170, 66, 126, 119, 108 und 132, 365, 65 (Abb. 5). Fïr einen bradyk. Schlag sind die Perioden 72, 66 und 65 zu kurz; man könnte sie deshalb leicht für verlängerte tachyk. Perioden ansehen. Da abor innerhalb der tachyk. Gruppen sonst nirgends ausgesprochene chronotrope Wirkungen zu sehen sind, halte ich es für richtiger, auch diese scheinbaren Ausnahmen in den beiden ersten Fällen durch vorzeitigen Abbruch, im letzten Falle durch verspätetes Einsetzen der tachyk. Schläge zu erklären. Die Perioden 72 und 66 wären unter dieser Voraussetzung verkürzte bradyk. Schläge, denen ein tachyk. Schlag folgt, der aber vereinzelt bleibt. Infolgedessen wird die nächste Periode, die eigentlich eine tachyk. ist, also die Perjode $129 \mathrm{bzw} .126$ verlängert, ähnlich wie in den Abb. 7 und 8 die Perioden 212 und 206 nicht durch Verlängerung des letzten tachyk. Schlages, sondern dadurch entstanden sind, daß die tachyk. Gruppe plötzlich abbricht und die folgende bradyk. Periode verzögert wird. Noch einleuchtender ist dies in Abb. 5. Hier leitet die Periode 65 die tachyk. Gruppe ein und wir haben schon erwähnt, daß falls diese einer extrasystolischen Reihe entspricht, ihr erstes Glied eigentlich noch zur bradyk. Gruppe gehört.

\section{Ergebnis:}

1. Die Vagusdruckerregung hat auf die bradyk. Perioden einen sehr starken, auf die tacbyk. Schläge dagegen einen im allgemeinen nur sehr schwachen, gerade noch nachweisbaren negativ chronotropen Einfluß.

2. Die tachyk. Gruppen können durch Vagusdruck bisweilen mehr oder weniger vollständig unterdrückt werden; sehr häufig kommt es nach Vagusdruck zu einem plötzlichen und vorzeitigen Abbrechen der Beschleunigungsgruppen, die dadurch unter Umständen bis auf einen einzigen Schlag reduziert werden können.

$$
\text { Digitalis. }
$$

Entsprechende Digitalisgaben erhöhen bekanntlich den Tonus der Hemmungsnerven. Es mußte daher von Interesse sein, die flüchtigen, 
durch Vagusdruck bedingten Wirkungen mit dem Effekte eines durch Digitalis dauernd gesteigerten Vagustonus zu vergleichen. Utberdies hat Wenckebach (l. c.) in seinem Falle „Lucianischèr" Perioden durch Digitalis die vorhandene Periodik in bestimmter Weise modifizieren können. „Es traten nämlich einerseits lange Tachykardien, anderseits sehr lange Pausen auf und der früher negative Vagusdruck wurde positiv. Der Rhythmus blieb aber dabei stets periodisch." Es war daher notwendig, auch bei unserem Patienten, bei dem ja das Vorhandensein Lucianischer Perioden ebenfalls in Erwägung stand, die Wirkung einer Digitalisbehandlung festzustellen.

Der Digitalisversuch wurde am 18. XII. mit der Darreichung von $0,5 \mathrm{~g}$ Pulv. folior. Digit. im Infus begonnen. Nach 6 Tagen wurde eine dreitägige Pause eingeschaltet. Vom 27. XII. an wurde die tägliche Dosis auf $0,8 \mathrm{~g}$ infundierten Blätterpulvers gesteigert und mit zweitägiger Unterbrechung (31.I. und 1.I.) bis zum 4. I. verabreicht. Der Patient erhielt also im ganzen $8,6 \mathrm{~g}$ pulverisierte Digitalisblätter der damals allerdings weniger wirksamen Droge. Erst am 5. I. kam es zu leichten Magenbeschwerden und Brechneigung. Darauf wurde die Behandlung abgebrochen und Atropin gegeben.

In Tab. IV sind die Ergebnisse der Kurvenmessung aus den in dieser Zeit gemachten Stichproben dargestellt. Während der ganzen ziemlich langen Behandlungsdauer bleibt die eigentümliche, periodische Herztätigkeit erhalten. Doch sind ähnlich wie im Wenckebachschen Falle die tachyk. Reihen schließlich (5. I.) wesentlich länger geworden. Utberdies wächst auch die Dauer der einzelnen Reizperioden, und zwar sowohl in den bradyk. als auch in den tachyk. Gruppen. Die bradyk. Perioden haben anfangs (19. XII.) einen Mittelwert von 1,23 Sek. Ein deutlicher Ausschlag wird erst am 24. XII. nach dem Gebrauche von $3 \mathrm{~g}$ Digitalispulver merklich. Der Durchschnittswert hat sich an diesem Tage auf 1,34 Sek. erhöht. Er berechnet sich dann am 28. XII. mit 1,39 Sek., am 29. XII. mit 1,45 Sek., am 3. I. mit 1,53 Sek. und am 5. I. mit 1,78 Sek., wobei Pausen bis zu 2,2 Sek. auftreten. Dazu kommt noch, daß vom 28. XII. an die bradyk. Gruppen nicht mehr aus 2; sondern durchwegs aus 3 Gliedern bestehen.

Die Verlängerung der tachyk. Reizperioden beginnt ungefähr gieichzeitig mit dem Wachsen der bradyk. Pulse, erreicht aber schon früher, nämlich am 29. XII. ihr Maximum. Der Mittelwert beträgt zu dieser Zeit 0,6 Sek., erhebt sich also ganz bedeutend über den normalen Durchschnitt von ungefähr 0,52 Sek. In dieser Beziehung besteht demnach ein Unterschied zwischen dem Effekte des Vagusdruckes und der toxischen Vaguserregung durch Digitalis. Im ersteren Falle ein häufiges Abreißen der tachyk. Gruppen, im letzteren auf der Höhe der Wirkung eine Zunahme ihrer Glieder, dort nur eine sehr geringe, hier dagegen 
eine ausgesprochene Verlängerung der einzelnen tachyk. Reizperioden. Interessant ist, daß der Vagusdruck auch während der Digitalisintoxikation die gleichen Resultate gibt wie früher, im wesentlichen also nur die bradyk. Perioden trifft. (Beispiele in Tab. IV.) Die Erhöhung des Vagustonus durch Digitalis tritt in den tachyk. Gruppen, abgesehen von der Verlangsamung der Reizperioden, noch in Form des periodischen $\mathrm{V}_{\mathrm{s}}$-Ausfalles zutage. Die zahlreichen Kreuze in Tab. IV, Stab 7 verraten, wie häufig schließlich diese Ausfälle werden. Die ihnen jedesmal vorangehende Zunahme des Intervalles $\mathbf{P}-\mathrm{R}$ bietet genau dasselbe Bild wie Taf. III, Abb. 4 vom 19. IV. und macht eine spezielle Illustration überflüssig.

Von der Wirkung der Digitalis kann also folgendes ausgesagt werden :

1. Die Periodik bleibt auch im Stadium der beginnenden toxischen Wirkung weiter bestehen.

2. Sowohl die Dauer der bradyk. (Pausen), als auch die der tachyk. Reizperioden wird verlängert.

3. Die Gliederzahl nimmt in den bradyk. und bei vorgeschrittener Vergiftung insbesondere in den tachyk. Gruppen zu.

\section{Atropin.}

Die Vagusausschaltung durch Atropin sollte einerseits über den Einfluß des normalen Vagustonus auf die Gruppenbildung Aufschluß gewähren und anderseits zeigen, inwieweit die durch Digitalisbehandlung erzeugten Veränderungen durch die toxische Erregung der Hemmungsnerven verursacht werden.

In Tab. V sind zunächst die Folgen einer am 4. XII. ausgeführten subcutanen Injektion von 1,5 mg Atropin dargestellt. Zum Vergleiche sind die in Tab. I enthaltenen Normalwerte heranzuziehen. In den ersten 10 Minuten nach der Injektion bleibt die periodische Herztätigkeit ziemlich unverändert. $O b$ die mäßige Zunahme der bradyk. und tachyk. Perioden auf die längere Ruhelage oder auf die bekannte vaguserregende Wirkung des Atropins bei seiner allmählichen Resorption zu beziehen ist, läßt sich nicht entscheiden. Nach 20 Minuten haben die bradyk. Perioden an Dauer noch weiter zugenommen. Erst nach 30 Minuten tritt eine stärkere Verkürzung derselben ein, während die Dauer der tachyk. Schläge ungefähr gleich bleibt.

Der zweite Teil von Tab. V enthält den zweiten Atropinversuch, der den Abschluß der Digitalisbehandlung bildet. Diesmal wurden 1,75 mg Atropin intravenös verabreicht. Auch hier bleibt die Periodik in den ersten 5 Minuten erhalten. Dagegen werden die Wirkungen der Digitalisbehandlung, wie ein Blick auf Tab. IV, Stab 7 lehrt, fast momentan aufgehoben. Schon eine Minute nach der Injektion sind bradyk. und tachyk. Perioden stark verkürzt. Besonders hochgradig ist die 


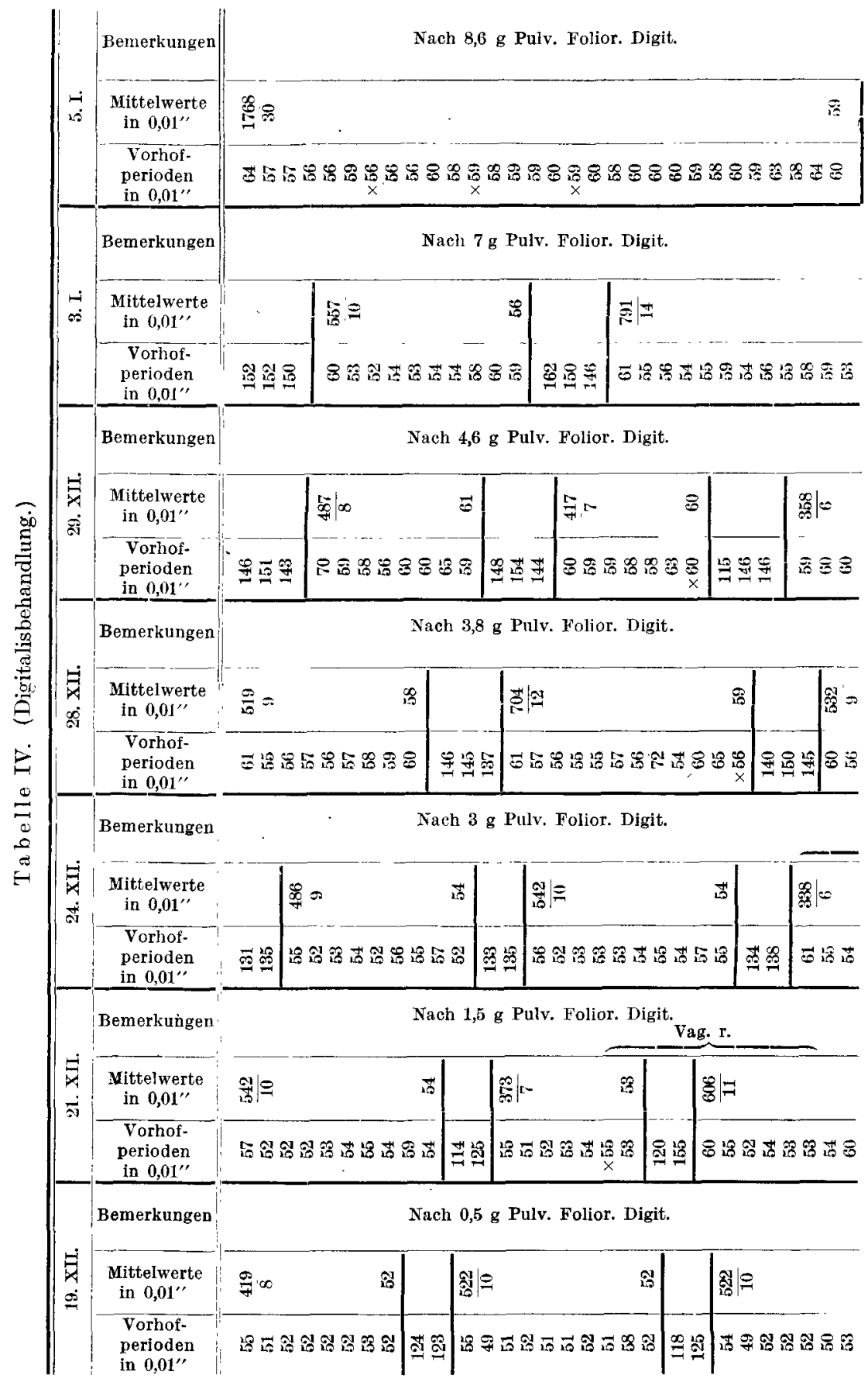


Nach 8,6 g Pulv. Folior. Digit.

\begin{tabular}{|c|c|c|c|}
\hline & & & \\
\hline & 影嗢 & . & $\ddot{x}$ \\
\hline 言芯商 & 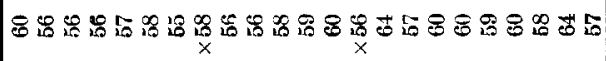 & 桶点 & 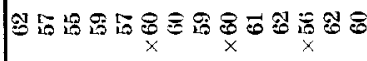 \\
\hline
\end{tabular}

Nach 7 g Pulv. Folior. Digit.

\begin{tabular}{|c|c|c|}
\hline 5 & & 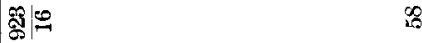 \\
\hline & 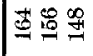 & 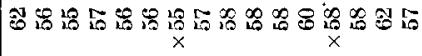 \\
\hline
\end{tabular}

Nach 4,6 g Pulv. Folior. Digit.

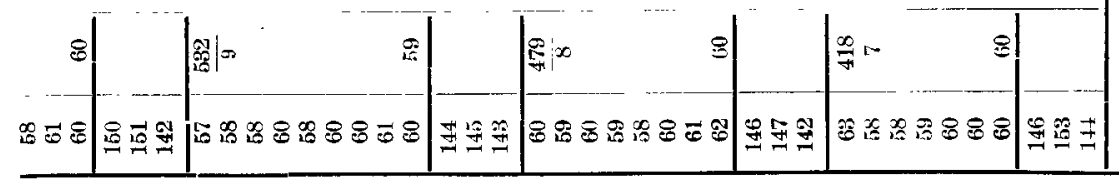

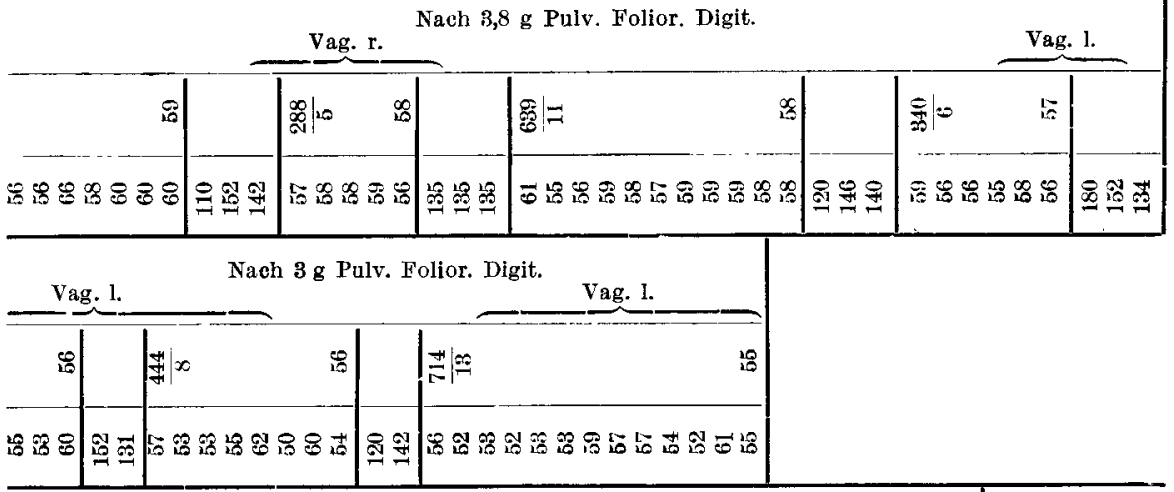

Nach 1,5 g Pulv. Folior. Digit.

\begin{tabular}{|c|c|c|c|c|c|c|}
\hline 18 & & 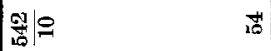 & & 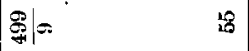 & & \\
\hline मूं & 芯㣽 & 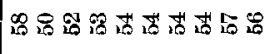 & $\underset{\exists}{\exists} \cong$ & 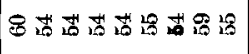 & $\exists$ & 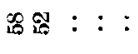 \\
\hline
\end{tabular}

Nach 0,5 g Pulv. Folior. Digit.

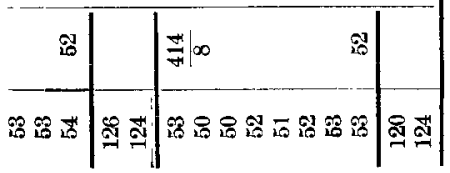




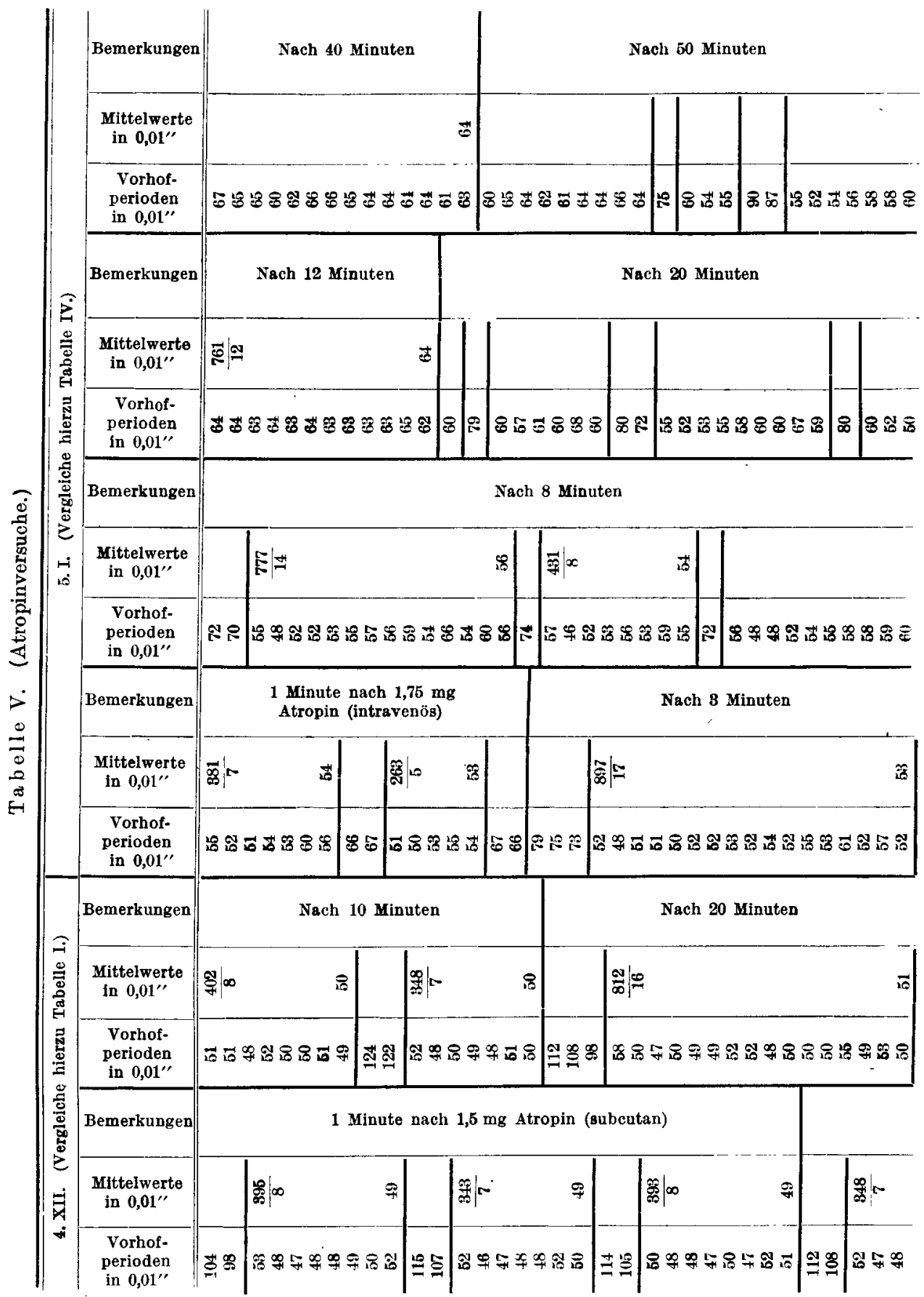




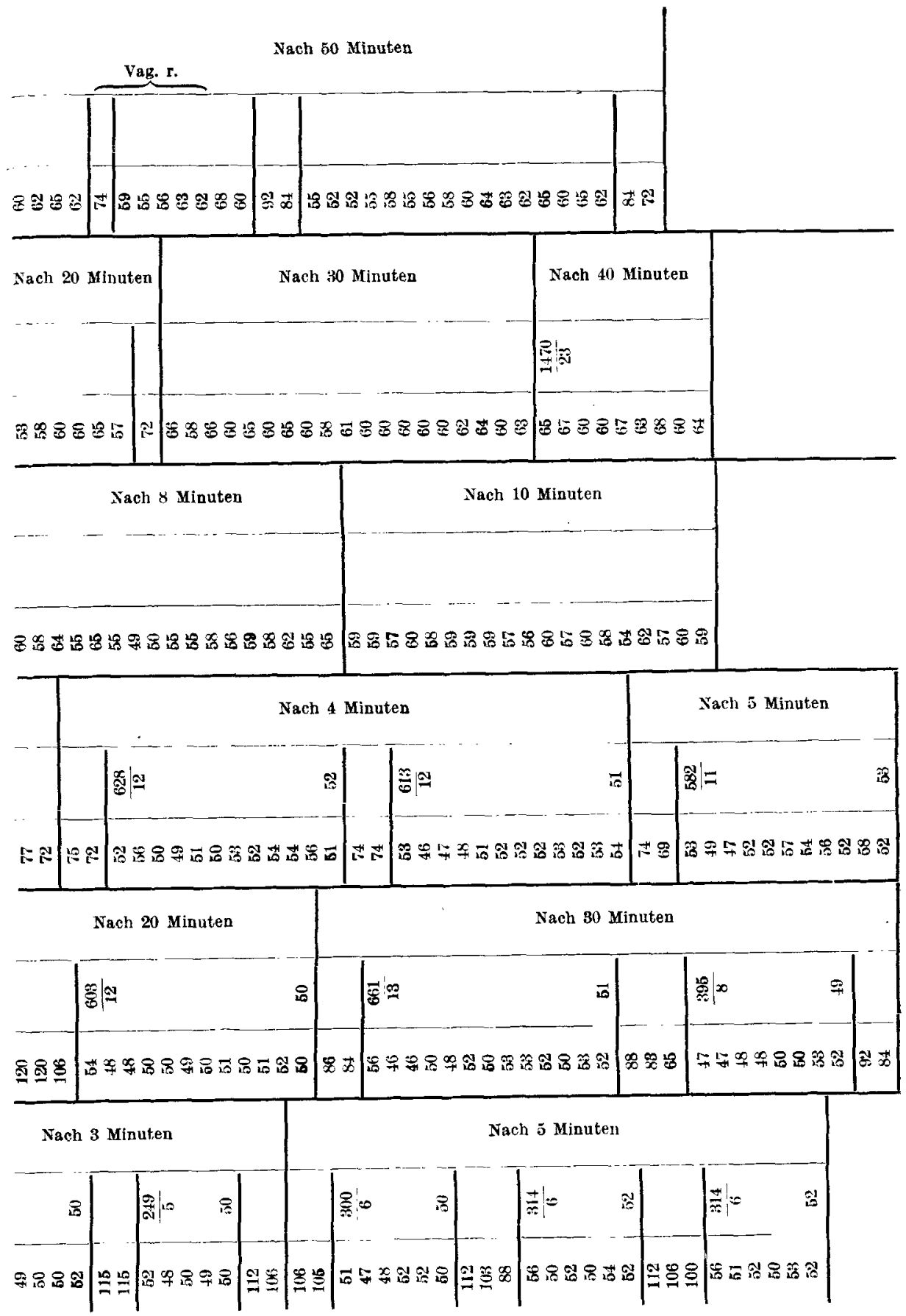


Verkürzung der bradyk. Schläge, die von 1,78 Sek. (Tab. IV) bis auf 0,67 Sek. durchschnittlicher Dauer abnehmen. Es wird also nicht nur der Digitaliseffekt beseitigt, sondern noch darüber hinaus eine beträchtliche Beschleunigung der bradyk. Perioden erzielt. Utberdies wird die während der Digitalisbehandlung auf 3 angestiegene Gliederzahl der bradyk, Gruppen wieder auf 2 herabgesetzt. Ebenso geht die Zahl der die tachyk. Gruppen zusammensetzenden Glieder herunter. Die Dauer der einzelnen tachyk. Perioden nimmt ebenfalls ab, doch sinkt ihr Mittelwert nicht unter den normalen Durchschnitt, ja es scheint sogar ein gewisser Rest von Verlangsamung zurückzubleiben. Ungefähr 8 Minuten nach der Injektion hört die Periodenbildung auf und macht zunächst einer arhythmischen Schlagfolge Platz. Die Vorgänge, welche nach der Atropininjektion zum Verschwinden der Periodik führen, sind außerordentlich schwer zu beurteilen. Selbst die wichtige Frage, ob die nach dem Aufhören der Gruppenbildung zurückbleibenden Pulse aus den bradyk. oder tachyk. Schlägen hervorgegangen sind, ist kaum sicher zu entscheiden. Hält man sich an die Art und Weise, in der die Periodik abgebaut wird (Tab. V, Stab 6, 8 Minuten nach der Injektion), so sieht man, daß die bradyk. Gruppen zunächst auf einen einzigen Schlag reduziert werden und dann verschwinden. Auf die letzte noch unzweifelhafte bradyk. Periode von 0,72 Sek. folgt eine lange Reihe von Schlägen, die ihrer Frequenz nach wenigstens anfangs sicher tachyk. Ursprunges sind. Dann aber beginnt die Schwierigkeit. Die Schlagfolge wird unregelmäßig und langsamer. Die meisten Reizperioden haben eine Dauer von fast 0,6 Sek., ein Wert, der weit oberhalb des Durchschnittes für die tachyk. Perioden vor der Atropininjektion liegt. Noch auffallender ist dies in der zweiten Minute. Die Herztätigkeit ist zu dieser Zeit ziemlich regelmäßig und die einzelnen Perioden sind auf 0,64 Sek. angewachsen. Man wird sich nicht leicht dazu versteben, das als Atropinwirkung auf die tachyk. Schläge anzusehen und eher annehmen, daß sich die bradyk. Perioden bis auf diesen Wert verkürzt hätten. Nun erscheinen aber 20 Minuten nach der Injektion wieder einige bradyk. Pulse; die zwischen diesen gelegenen rascheren Schläge erreichen aber ebenfalls zum Teil eine Dauer von 0,6 Sek. und darüber. Die Periodik hört dann wieder auf und in der 30. und 40. Minute erscheinen abermals jene Perioden von durchschnittlich 0,64 Sek. Dauer, die für bradyk. Pulse zu kurz und für tachykarde zu lang sind. Auch in der 50. Minute herrschen anfangs diese fraglichen Perioden vor. Nunmehr tauchen aber wieder einzelne bradyk. Schläge auf; sofort verkürzen sich die anschließenden Perioden auf 0,52-0,55 Sek., um dann rasch wieder auf den früheren Wert anzuwachsen, eine Erscheinung, die sich in ähnlicher Weise noch mehrfach wiederholt. Es liegt daher nahe, in dem Wegfall der Pausen ebenso den Grund für die Verlängerung, 
wie in ihrem Auftreten die Veranlassung für die Verkürzung der tachyk. Perioden zu erblicken. Doch muß immerhin zugegeben werden, daß die ganze Beobachtung infolge der vielfachen Unterbrechung der Registrierung zu lückenhaft ist, um jeden Zweifel an dieser Auffassung auszuschließen. Ist sie aber richtig, dann wäre das Verschwinden der Periodik selbst weiter nicht merkwürdig, da ja schließlich der frequentere Rhythmus dominiert.

Zusammenfassend können wir folgendes sagen:

1. Atropin verkürzt am unvergifteten Herzen die bradyk. Perioden, ist aber ohne Einfluß auf die Dauer der tachyk. Schläge. Daraus geht hervor, daß durch die physiologische Vaguserregung (Vagustonus) die Schlagfrequenz nur innerhalb der bradyk. Gruppen nachweisbar gehemmt wird.

2. Atropin beseitigt nicht nur die durch Digitalis hervorgerufene Verlangsamung der bradyk. Perioden, sondern erzeugt überdies eine weitere Beschleunigung derselben, indem es die toxische Vaguserregung sowie den reflektorischen Vagustonus aufhebt.

3. Die durch Digitalis bedingte Verlangsamung der tachyk. Perioden wird durch Atropin ebenfalls zum Verschwinden gebracht. Eine weitere Beschleunigung der tachyk. Schläge erfolgt jedoch nicht, es scheint sogar ein Rest von Verlangsamung zurückzubleiben.

4. Atropin in größerer Dosis $(1,75 \mathrm{mg}) \mathrm{kann}$ vorübergehend zum Aufhören der Periodenbildung führen, und zwar wahrscheinlich durch Unterdrückung der bradyk. durch die tachyk. Schläge.

5. Es scheint, daß bei Wegfall der bradyk. Perioden die tachyk. Schläge länger werden. Umgekehrt dürften beim Wiederauftreten der Pausen die tachyk. Perioden kürzer werden.

\section{Acceleransreizung.}

Die folgenden Versuche betreffen den Einfluß der Beschleunigungsnerven auf die Periodenbildung und umfassen die Wirkung der körperlichen Arbeit, des Lagewechsels, der psychischen Erregung, der Injektion von Adrenalin und schließlich den Effekt einer'Schilddrüsenbehandlung. Sie gehen ebenfalls von dem Gedanken aus, für die Gleichheit bzw. die Verschiedenheit der Reizbildungsstellen beider Gruppen, und zwar hier aus ihrem Verhalten gegenüber dem Herzsympathicus Beweismaterial zu gewinnen.

\section{Arbeitsversuche.}

Bei diesen Experimenten hatte der Patient 5-30 Kniebeugen auszuführen. Er vertrug selbst die größten der ihm hier zugemuteten Anstrengungen ohne besondere Beschwerden. Nach geleisteter Arbeit 
legte sich der Patient sofort nieder und die Registrierung konnte beginnen.

Tab. VI gewährt im ersten Teile die Ubersicht über 4 Arbeitsversuche am 17. IV, 18. IV., 19. IV. und 28. XII., denen die zum Vergleiche nötigen Ruhewerte vorangeschickt sind. Im Versuche vom 18. IV. finden sich mit 5, 10 und 15 Kniebeugen abgestufte Leistungen. Das Experiment vom 28. XII. ist in die Digitalisversuchsreihe eingeschaltet und mit Tab. IV unter demselben Datum zu vergleichen.

Die periodische Herztätigkeit erleidet durch Arbeit, und zwar schon durch die geringe Leistung von 5 Kniebeugen (18. IV. b.) recht einschneidende Veränderungen. Die Gruppenbildung geht anfangs durchgehends auf kürzere oder längere Zeit verloren. Auf dieses erste Stadium folgt ein zweites, in dem die Periodik allmählich wieder zum Vorschein kommt. Wir betrachten zunächst die leichtverständlichen Verhältnisse im zweiten Stadium.

Die Dauer der bradyk. Perioden wird in allen Fällen bedeutend verkürzt. Mit steigender Leistung ist diese Wirkung auch stärker und anhaltender ausgeprägt. Die durch Digitalis erzielte Verlängerung der bradyk. Perioden wird durch Anstrengung nicht nur beseitigt, sondern es kommt auch hier zu einer Verkürzung unter den gewöhnlichen Durchschnitt.

Die Dauer der tachy k. Perioden bleibt nach kleinen Anstrengungen unverändert, nach größeren Leistungen wird sie ebenfalls kleiner, doch ist der Effekt ziemlich gering und viel flüchtiger als in den bradyk. Perioden. Ein etwas größerer und länger währender Ausschlag findet sich nur im Versuche vom 28. XII. Hier sind jedoch die tachyk. Reizperioden durch die vorangegangene Digitalisbehandlung bedeutend verlängert. 25 Kniebeugen heben vorübergehend auch diesen Teil der Digitaliswirkung auf, vermögen aber nicht eine weitere Verkürzung unter den normalen Durchschnitt zustande zu bringen.

Die Gliederzahl der tachyk. Gruppen wird durch Arbeit jeder Größe beeinflußt und nach stärkeren Anstrengungen in allen Fällen für längere Zeit wesentlich vermindert.

Schwieriger zu deuten ist das bisher beiseite gelassene erste Stadium des Verschwindens der Periodik. Es ist das weitaus interessantere, da ja die Erkenntnis der Ursachen für das Aufhören und Wiedererscheinen der Periodik offenbar das Verständnis der Gruppenbildung erschließen müßte.

Unmittelbar nach der Arbeit tritt an Stelle der periodischen eine ziemlich regelmäßige Herztätigkeit. Die einzelnen Reizperioden sind zu dieser Zeit durchwegs kürzer als die bradyk. Pulse, dagegen im allgemeinen länger als die tachyk. Perioden. Nur im Beginne der Registrierung pflegen sie noch in das Bereich der längeren tachyk. 
Pulse des Ruhezustandes zu fallen. Im weiteren Verlaufe nimmt ihre Frequenz allmählich nicht unbeträchtlich ab, bleibt aber immer noch weit hinter jener der bradyk. Schläge zurück. Auch hier ist die wichtige Frage zu beantworten, wem diese Perioden entsprechen. Da die ganze Veränderung durch Arbeit bzw. durch den mit ihr verknüpften Sympathicusreflex hervorgerufen wird, ist es von vornherein wahrscheinlich, daß es sich um verkürzte bradyk. Perioden handeln dürfte. Dafür spricht auch das allmähliche Abklingen der Beschleunigung. Hingegen wäre nicht gut einzusehen, wieso die tachyk. Perioden nach der Arbeit langsamer werden sollten. Da wir aber in dem Verluste der Periodik im vorangegangenen Kapitel ein Moment kennengelernt haben, das an sich zu einer Verlangsamung der tachyk. Pulse zu führen scheint, ist diese Utberlegung nicht ganz zwingend. Es bedarf deshalb noch anderer Beweise und diese liefert die Art und Weise, wie die Periodik wieder in Gang kommt. Es ist nicht immer geglückt, den Übergang, der sich ganz plötzlich vollzieht, zu erfassen. Im Versuche vom 17. IV. wurde z. B. die Registrierung zwischen den Kurvenstücken b und c (Tab. VI) nur einen Augenblick unterbrochen. Die Periodik scheint nun gerade im Beginne von c zurückzukehren; doch besteht darüber keine Sicherheit. In den übrigen Versuchen der Tab. VI ist dagegen der richtige Moment nicht versäumt worden und die Wiederkehr der Periodik vollzieht sich unter unseren Augen. Das geschieht manchmal in so verdeckter Weise, daß der Ubergangsmechanismus leicht mißdeutet werden kann. Im Kurvenstück $b$ des Versuches vom 18. IV., Tab. VI, liegt z. B. die irrige Annahme nahe, daß nach einem vorübergehenden Durcheinander etwas arhythmischer Herzschläge die Gruppenbildung mit den aus der Reihe der übrigen Pulse scharf hervortretenden Perioden 85 und 88 einsetzt. In Wirklichkeit aber ist es die diesen vorangehende unscheinbare Reizperiode von 52 , die den Umschwung einleitet, gerade so, wie bei vorhandener Disposition zum Alterans oft eine kleine Frequenzschwankung genügt, um den Wechselschlag des Herzens auszulösen. Daß es sich wirklich so verhält, geht aus den übrigen Versuchen und besonders aus dem Experimente vom 19. IV. hervor. Hier beginnt nach $35 \mathrm{Kniebeugen} \mathrm{eine} \mathrm{lange} \mathrm{Reihe}$ der beschriebenen, nicht in Gruppen angeordneten Pulse. Die ersten Glieder reichen mit ihrer Frequenz noch in das Gebiet der tachyk. Perioden, um es aber, allmählich langsamer werdend, bald weit zu überschreiten. Da erscheint plötzlich als 34. Schlag eine kürzere Periode, die nach ihrer Größenordnung wieder zu den tachyk. Pulsen zu zählen ist. Sie ist die erste noch rudimentäre tachyk. Gruppe und bedingt immer, wenn sie erscheint, eine sprungweise Verlangsamung in der durch sie durchbrochenen Pulsreihe, deren Frequenz bis dahin nur nach und nach, wenn auch nicht ganz regelmäßig abgesunken ist. 


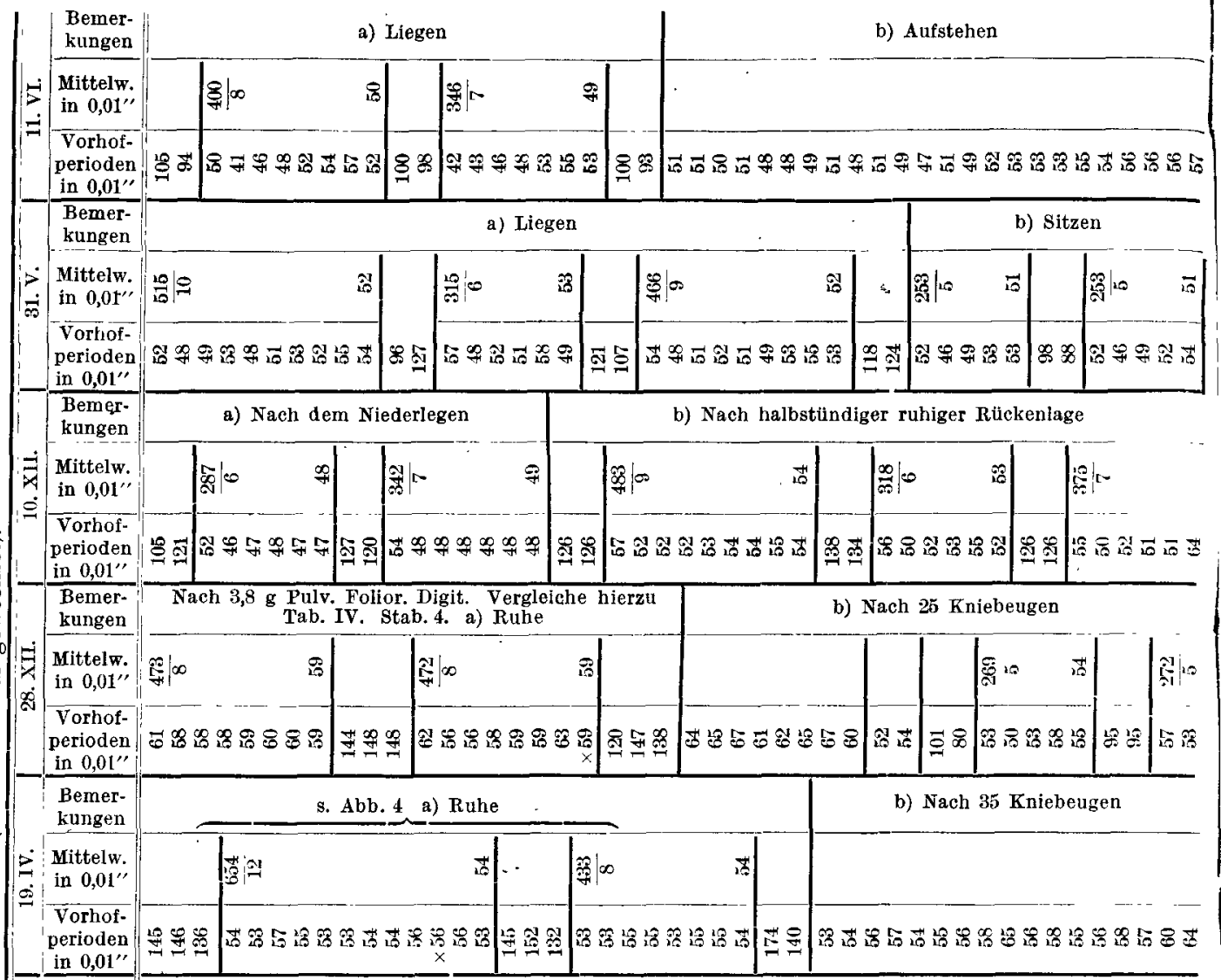

Bemer-

kungen

Mittelw. in $0,01^{\prime}$

Vorbof$\therefore$ perioden

$\approx$ in 0,01

$\infty$ Bemerkungen

Mittelw. in $0,01^{\prime \prime}$

Vorhof-

perioden in $0,01^{\prime \prime}$

Bemer-

kungen

$>$ Mittelw.

光

c) Nach 15 Kniebeugen

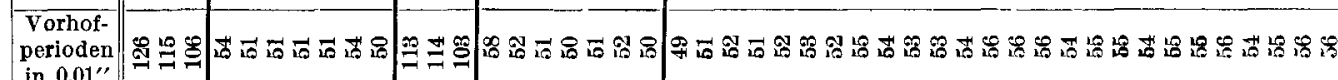

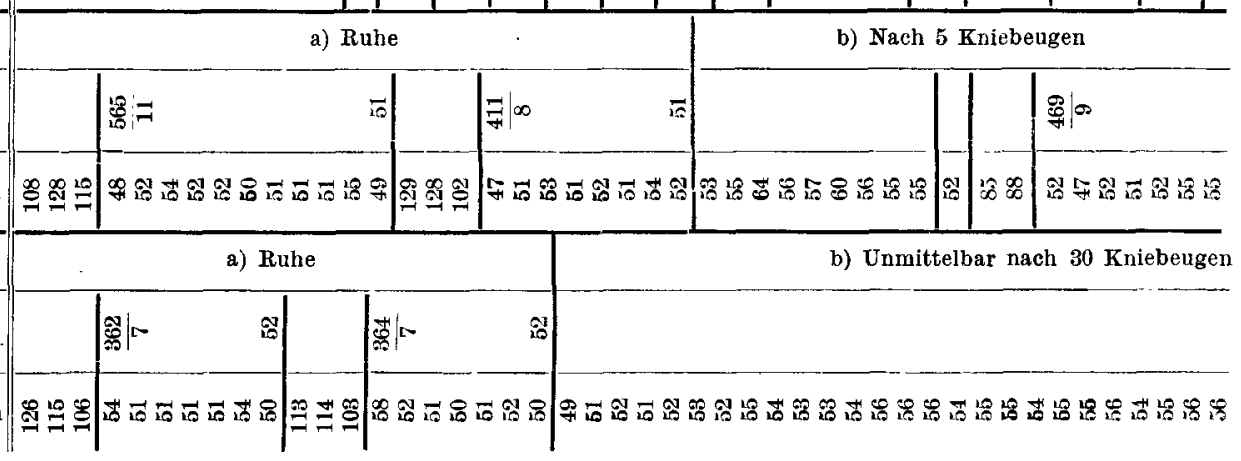


b) Aufstehen

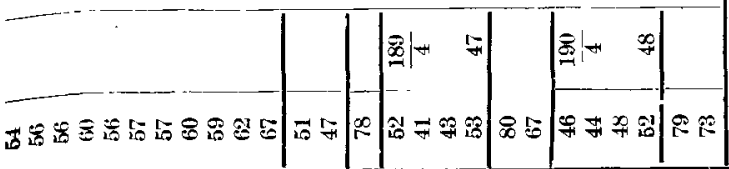

b) Sitzen

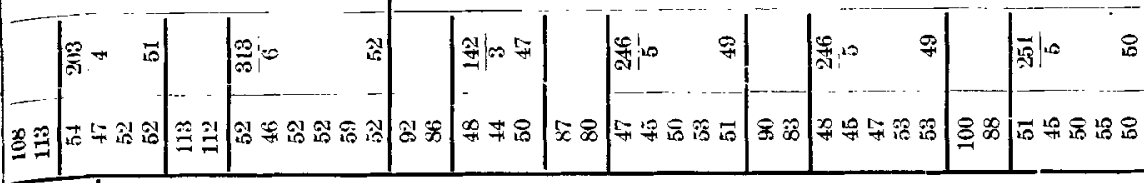

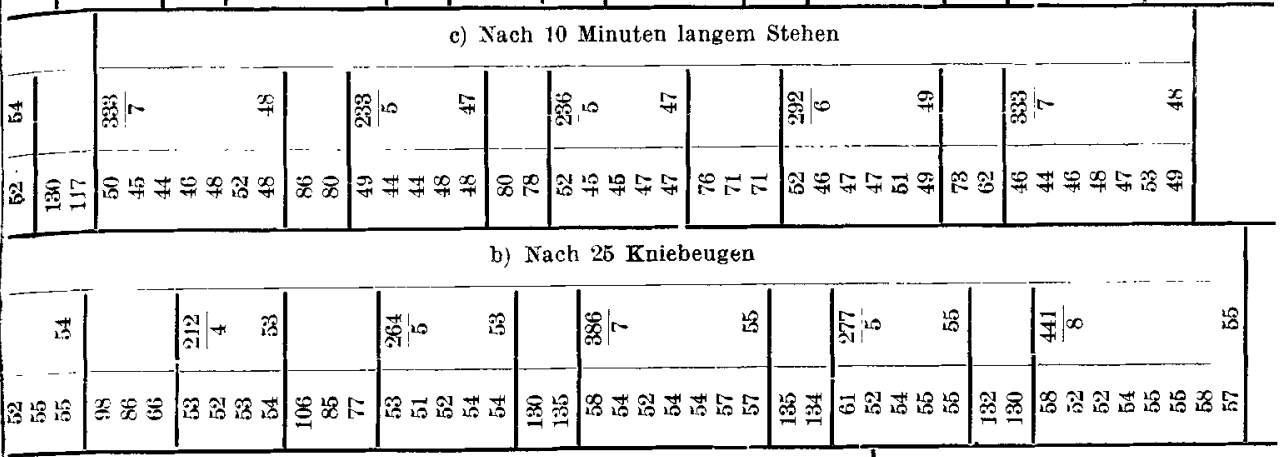

b) Nach 35 Kniebeugen

\begin{tabular}{|c|c|c|c|c|c|c|}
\hline & & & 的 & & $\left|\frac{30}{n}\right|^{4} \quad$ 落 & \\
\hline 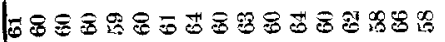 & 임 & $\therefore 5$ & 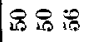 & $\infty$ & 용ำ & 8 \\
\hline
\end{tabular}

d) Nach 15 Kniebeugen

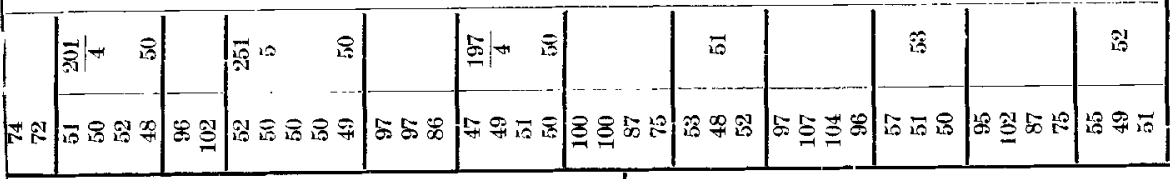

b) Nach 5 Kniebeugen

\begin{tabular}{|c|c|c|c|c|c|c|c|c|c|c|c|}
\hline$\infty$ & & 部余 & & 영 & & & & & & & $\mid$ \\
\hline 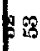 & 象央 & 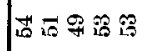 & 正为 & 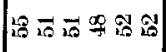 & $5 \stackrel{2}{g}$ & 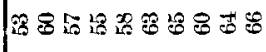 & 관 운 & 芯にこの8 & 6 & |゙่ & \\
\hline
\end{tabular}

c) Fortsetzung von b Dach ganz kurzer Unterbrechung

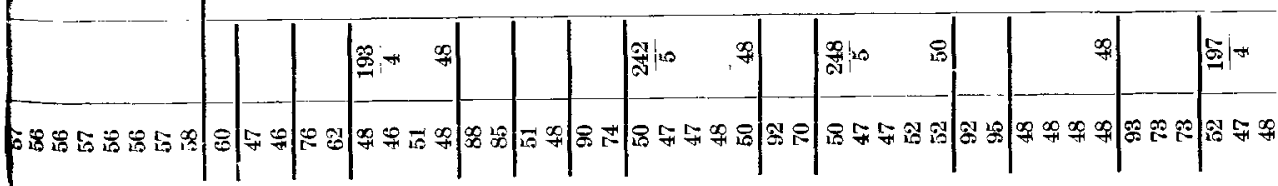


Aber schon nach zwei dieser nicht mehr verkennbaren bradyk. Perioden folgt eine jetzt schon aus 3 Gliedern bestehende tachyk. Gruppe. Die Gliederzahl der tachyk. Gruppen wächst dann allmählich weiter an und auch die bradyk. Schläge, die noch immer wesentlich kürzer sind als vor der Arbeit, nehmen von Gruppe zu Gruppe zu, bis sie endlich ihre gewöhnliche Länge erreichen. Besonders scharf markiert sich der Wiederbeginn der Periodik im Versuche vom 28. XII. (Tab. VI, Stab 5) durch die eben erwähnte sprungweise Verlangsamung der den ersten tachyk. Schlägen folgenden bradyk. Perioden $(101,80)$. Diese auffallende Erscheinung erinnert an die im vorangehenden Kapitel gemachte Beobachtung, daß sich bradyk. und tachyk. Pulse in der Weise beeinflussen, daß der Wegfall der ersteren die letzteren, das Wiedererscheinen der letzteren aber die ersteren verlängert.

Als Resulta, der Arbeitsversuche sind folgende Punkte hervorzuheben:

1. Körperliche Arbeit hebt die Periodik vorübergehend auf. Die Beschleunigungsgruppen werden durch kürzere oder längere Reihen von Pulsen verdrängt, die aus den stark verkürzten bradyk. Perioden hervorgehen.

2. Der Wiederbeginn der Periodik erfolgt plötzlich. Er wird eingeleitet durch das Auftauchen von ein oder zwei tachyk. Schlägen und sprungweiser Verlangsamung der ihnen folgenden zu diese Zeit noch stark verkürzten bradyk. Perioden.

3. Auch nach dem Wiederbeginn der Periodik sind die bradyk. Schläge noch bedeutend, die tachykarden hingégen nur wenig verkürzt. Die Gliederzahl der tachyk. Gruppen ist wesentlich herabgesetzt.

\section{Lagewechsel.}

Die Beobachtung, daß schon kleinste Leistungen verhältnismäßig bedeutende Wirkungen auszulösen vermochten, führte dazu, den Einfluß des Lagewechsels auf die periodische Herztätigkeit zu prüfen. Aus zahlreichen Experimenten sind die im zweiten Teile der Tab. VI zusammengestellten Beispiele gewählt. Der erste Versuch vom 10. XII. (Stab 6) vergleicht den Zustand, nachdem sich der Patient niedergelegt hat (a) mit jenem nach halbstündiger ruhiger Rückenlage (b) und nach 10 Minuten langem Stehen (c). Der zweite Versuch vom 31. VI. (Stab 7) zeigt, wie sich die Periodik beim Liegen, Sitzen und Stehen verhält und der dritte Versuch vom 11. VI. (Stab 8) demonstriert den Effekt beim plötzlichen Erheben aus der Ruhelage. Die Ergebnisse dieser Experimente, deren Details leicht aus Tab. VI zu entnehmen sind, gleichen in jeder Beziehung den durch Arbeitsleistung erhaltenen Resultaten und sind wohl auf denselben Faktor - die reflektorische 
Acceleransreizung - zurückzuführen. Der Hauptsache nach findet man :

1. Eine sehr bedeutende Verkürzung der bradyk. Perioden und eine geringe, aber noch nachweisbare Beschleunigung a uch der tachyk. Schläge beim Ủbergange vom Liegen zum Sitzen bzw. Stehen. Gleichzeitig verringert sich die Gliederzahl der tachyk. Gruppen (31. V.).

2. Nach längerer R uhelage wachsen nicht nur diebradyk., sondern auch die tachyk. Perioden stärker an (10. XII.).

Am besten ausgeprägt sind die Veränderungen beim jähen Aufstehen bzw. Aufsetzen des Untersuchten. Die Periodik kann dann vorübergehend wie nach körperlicher Arbeit vollständig verschwinden. Im Versuche vom 11. VI. b ist sehr gut zu erkennen, daß die stark verkürzten bradyk. Pulse die tachyk. Gruppen verdrängt haben. Es geht dies aus der langsam zunehmenden Abnahme der Pulsfrequenz recht klar hervor. Auch der Utbergang zur Gruppenbildung vollzieht sich genau so wie sonst nach körperlicher Anstrengung.

Zu erwähnen ist noch, daß die Änderungen der periodischen Herztätigkeit im eben besprochenen Sinne sich zwar nicht vollständig, aber doch zum größten Teile zurückbilden, sobald dieselbe Lage dauernd beibehalten wird. Steht also der Patient durch längere Zeit, so stellt sich die Periodik, auch wenn sie beim Aufstehen verlorenging, bald wieder her. Nur sind die tachyk. Gruppen und die bradyk. Reizperioden kürzer als im Liegen (10. XII. c).

\section{Psychische Erregung.}

Es ergab sich wiederholt Gelegenheit, den Patienten im Zustande psychischer Erregung zu untersuchen. Dabei zeigte sich, daß durch psychische Erregung die gleichen Veränderungen hervorgerufen wurden, wie durch körperliche Arbeit bzw. Lagewechsel. Auf das Moment der psychischen Erregung mußte namentlich bei der Beurteilung kleiner Eingriffe geachtet werden. Schon die Vorbereitungen zu einer subcutanen oder intravenösen Injektion genügten anfangs zur Unterdrückung der Periodenbildung. Später, als der Patient die Harmlosigkeit dieser Prozeduren erkannt hatte und sie mit Gleichgültigkeit über sich ergehen ließ, blieben auch diese Störungen aus.

\section{Adrenalin.}

Ähnlich, wie wir der Druckerregung des Vagus die toxische Steigerung des Vagustonus durch Digitalis gegenübergestellt haben, versuchten wir zur reflektorischen Erregung des Accelerans ein Gegenstück in seiner pharmakologischen Beeinflussung zu gewinnen. Zu diesem Zwecke 
bedienten wir uns zunächst der subcutanen Injektion von Adrenalin, das in zwei Versuchen in der Gabe von 0,75 bzw. 1,25 ccm einer Lösung von Adrenalin. hydrochlor. Parke-Davis am 19. I. und 21. I. 1918 gegeben wurde. Die zahlenmäßige Darstellung dieser beiden Versuche liefert Tab. VII. Die Abb. 11 vom 21. I. auf Taf. V illustriert eine Phase 1 Stunde nach der Injektion.

Der langsamen Resorption wegen macht sich die Adrenalinwirkung in beiden Versuchen erst relativ spät, und zwar ungefähr 20 Minuten nach der Injektion bemerkbar. Die Veränderungen, die beim Abbruche der beiden Versuche, d. i. 45 bzw. 60 Minuten nach der Injektion noch nicht ganz abgeschlossen sind, bestehen in einer Verkürzung sowohl der bradyk. als auch der tachyk. Perioden. Namentlich die letztere ist der Adrenalinwirkung eigentümlich; während bei der reflektorischen Acceleransreizung die tachyk. Schläge nur wenig beeinflußt werden, sinkt ihre mittlere Dauer in beiden Versuchen bis auf 0,46 Sek. Dabei ist noch zu berücksichtigen, daß die lange Ruhelage dem durch Adrenalin erzeugten Ausschlag entgegenwirkt, so daß dieser, abgesehen von der vorzeitigen Unterbrechung der Beobachtung, schon aus diesem Grunde wahrscheinlich zu klein ausfällt. Die Zahl der Glieder in den tachyk. Gruppen wird durch Adrenalin zwar verringert, jedoch nicht so markant, wie bei Lagewechsel und körperlicher Anstrengung. Nach dieser Richtung macht sich wohl ebenfalls die Gegenwirkung der langen Ruhelage geltend.

Aus dem Versuchsverlauf vom 21. I. ist die 60 Minuten nach der Injektion registrierte Abb. 11 herausgegriffen. Obwohl diese Abbildung nicht mehr zeigt, als ohnehin aus Tab. VII zu entnehmen ist, habe ich sie dennoch aufgenommen, weil sie besser als das übrige Kurvenmaterial den früher erwähnten Formunterschied der P-Zacken in den bradyk. und tachyk. Gruppen erkennen läßt. Die Differenz ist gegen Ende des Versuches besonders ausgesprochen, wo die Schlagfrequenz um so viel rascher geworden ist.

Die Adrenalinwirkung nach subcutaner Injektion besteht demnach:

1. In einer Verkürzung der bradyk. sowie a uch dertachyk. Perioden,

2. in einer Abnahmeder Gliederzahldertachyk. Gruppen.

Schilddrüsenbehandlüng.

Durch längere Darreichung von Schilddrüse oder Schilddrüsenpräparaten entsteht bekanntlich in vielen Fällen eine Tachykardie, die ebenfalls auf Beeinflussung des Herzsympathicus bezogen wird [Biedl1)]. Gegenüber dem Adrenalin sind die durch Schilddrüse hervorS. 94 .

1) Biedl, Innere Sekretion. Urban und Schwarzenberg. Berlin-Wien 1910. 
gerufenen Wirkungen zwar schwerer und unsicherer auslösbar, aber dafür viel nachhaltiger. Die Behandlung begann am 21. II. mit einer täglichen Dosis von $1 \frac{1}{2}$ Tabletten à $0,3 \mathrm{~g}$, die nach und nach auf $5 \mathrm{Ta}$ bletten pro die erhöht wurde. Am 13. III. wurde die weitere Verabfolgung von Schilddrüse eingestellt. Während dieser Zeit blieb das Allgemeinbefinden des Patienten ungestört, das Körpergewicht nahm von $63 \mathrm{~kg}$ (21. II.) auf $61^{1 / 2} \mathrm{~kg}$ (13. III.) ab. Die Harnmenge war nie auffallend vermehrt, die hüufig wiederholte Prüfung auf Zuckerausscheidung war immer negativ, der Blutdruck schwankte zwischen 100 und $125 \mathrm{~mm} \mathrm{Hg}$. Die Herztätigkeit kontrollierten zahlreiche elektrographische Aufnahmen. Aus diesen sind ausgewählte Stücke in Tab. VIII verarbeitet und teilweise in Taf. V, Abb.12, 13 und 14 reproduziert.

In der ersten Zeit der Schilddrüsenbehandlung bleibt die Herztätigkeit im wesentlichen unverändert. Ob die geringe Verkürzung der bradyk. Perioden am 27. II. schon als Schilddrüsenwirkung anzusehen ist, erscheint zweifelhaft, da auch sonst Unterschiede dieser Größenordnung nicht selten sind. Dagegen fällt am 1. III. eine weitgehende Verkürzung der tachyk. Gruppen auf, die stellenweise aus zwei oder gar nur aus einem Gliede bestehen. Auch am 5. III. trägt die Herztätigkeit noch denselben Charakter (Abb. 12). Am 9. III. sind zwar die tachyk. Gruppen wieder besser ausgebildet, fallen aber dafür manchmal ganz aus, so daß bis 6 bradyk. Pulse aufeinanderfolgen. Die bradyk. Perioden selbst sind jetzt bereits unzweifelhaft verkürzt. Am nächsten Tage (10. III.) scheint die Periodik anfangs vollständig zu fehlen, doch finden sich in dem zweiten tabellierten Kurvenstück vom 10. III. wieder einzelne kürzere Perioden. Am 11. III. bleiben sie ganz aus, tauchen dann aber am 12. III. in kleinen rudimentären Gruppen nochmals auf. Abb. 13 illustriert einen dieser isolierten kurzen Schläge. Das Bild entspricht hier mit der dem vorzeitigen Schlage folgenden unvollständig kompensierenden Pause ganz dem einer aurikulären Extrasystole. Es ist aber auffallend, daß die oft nur ganz geringfügige Verlängerung manchmal in gleicher oder annähernd gleicher Weise auch den zweiten der verkürzten Periode folgenden Schlag betrifft, z. B. in der Pulsreihe 106, 93, 98-59-100, 98 vom 1. III. Tab. VIII Stab 3. Noch ein Detail scheint mir in Abb. 13 erwähnenswert, nämlich der Wechsel in der Gestalt der P-Zacken, weil dieser zur Zeit der periodischen Herztätigkeit immer nur in den bradyk. Gruppen beobachtet werden konnte. Mit dem 13. IIT. hatte die Periodenbildung vollständig aufgehört und blieb bis zum 24. III. verschwunden, obwohl schon am 13. III. die Schilddrüsenbehandlung sistiert wurde. An ihre Stelle trat eine mehr weniger arhythmische Herztätigkeit, deren respiratorischer Charakter sich leicht feststellen ließ. Die langen Pulsperioden fallen konstant an das Ende der Exspiration bzw. in 
H. Winterberg: Zur Kenntnis

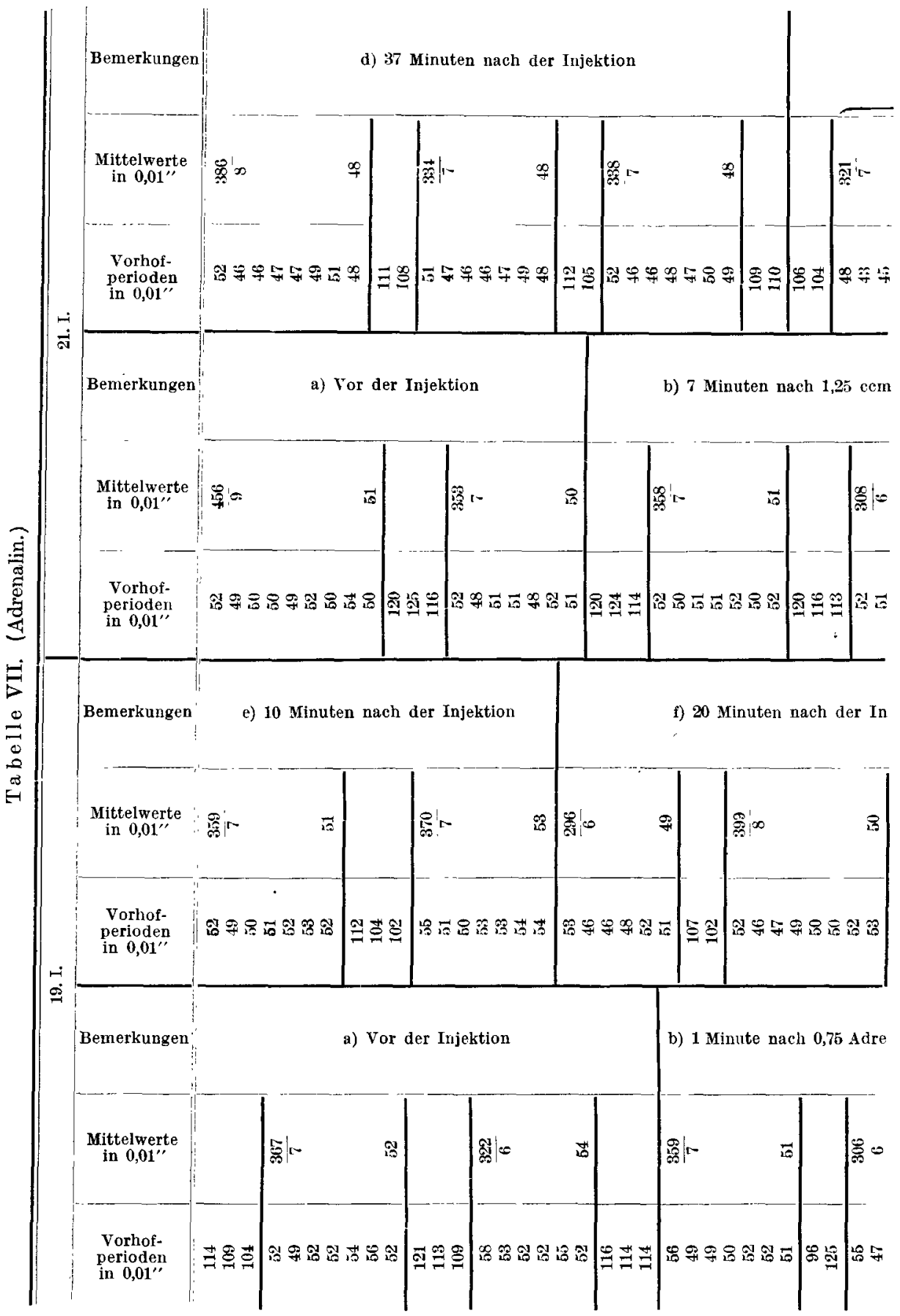


e) 60 Minuten nach der Injektion
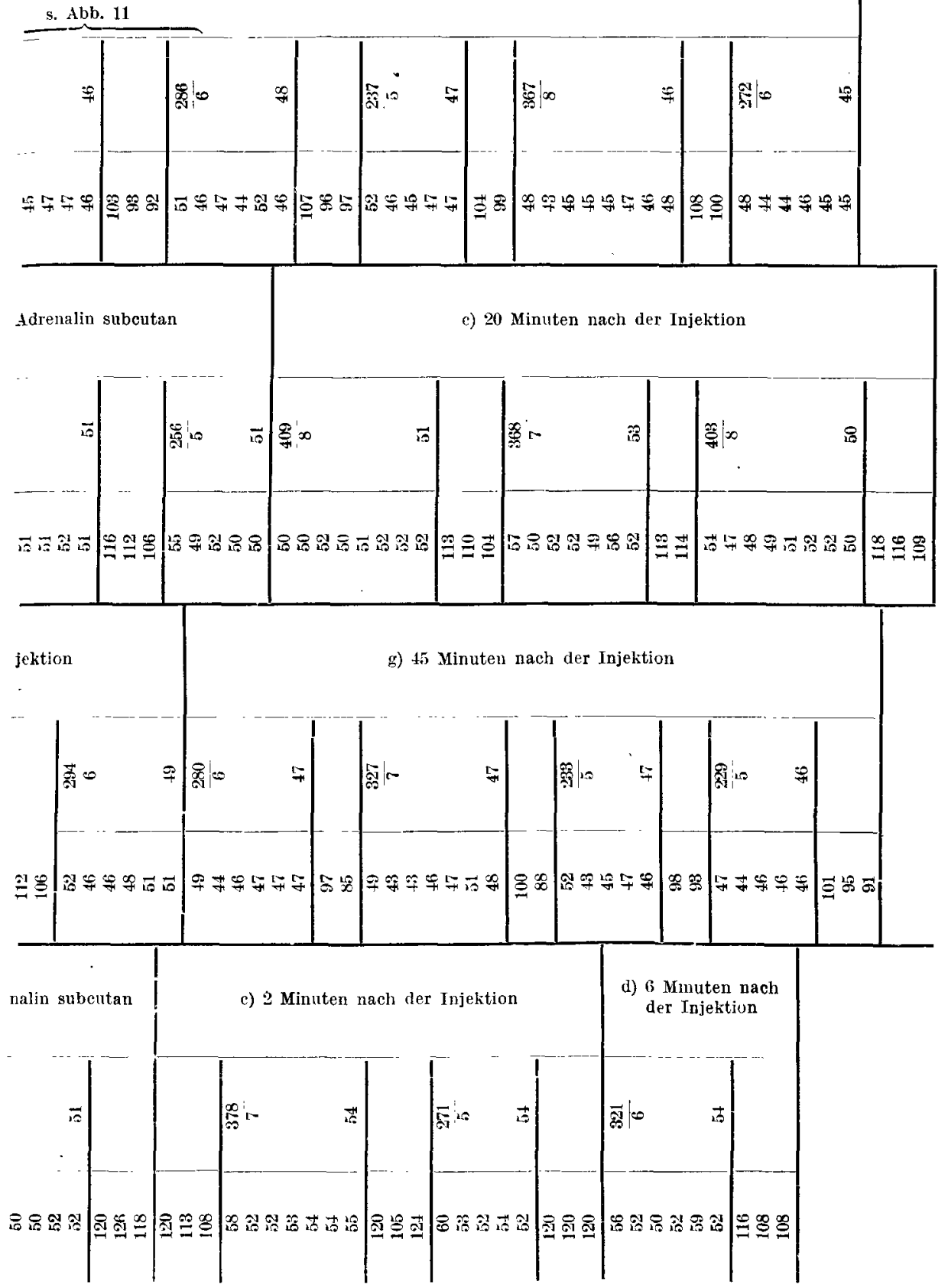
Tabelle

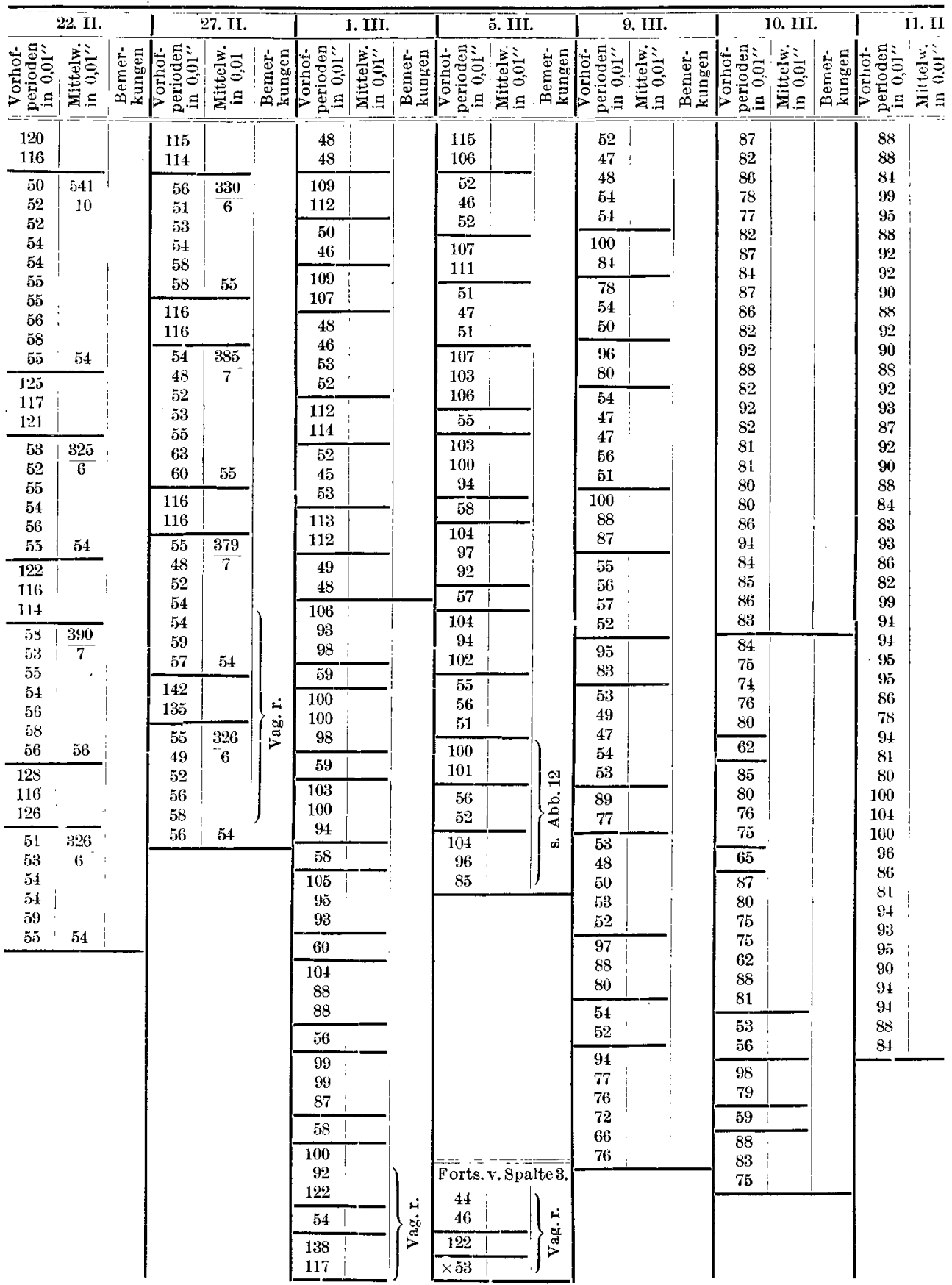


(Schilddrüsen Behandlung.)

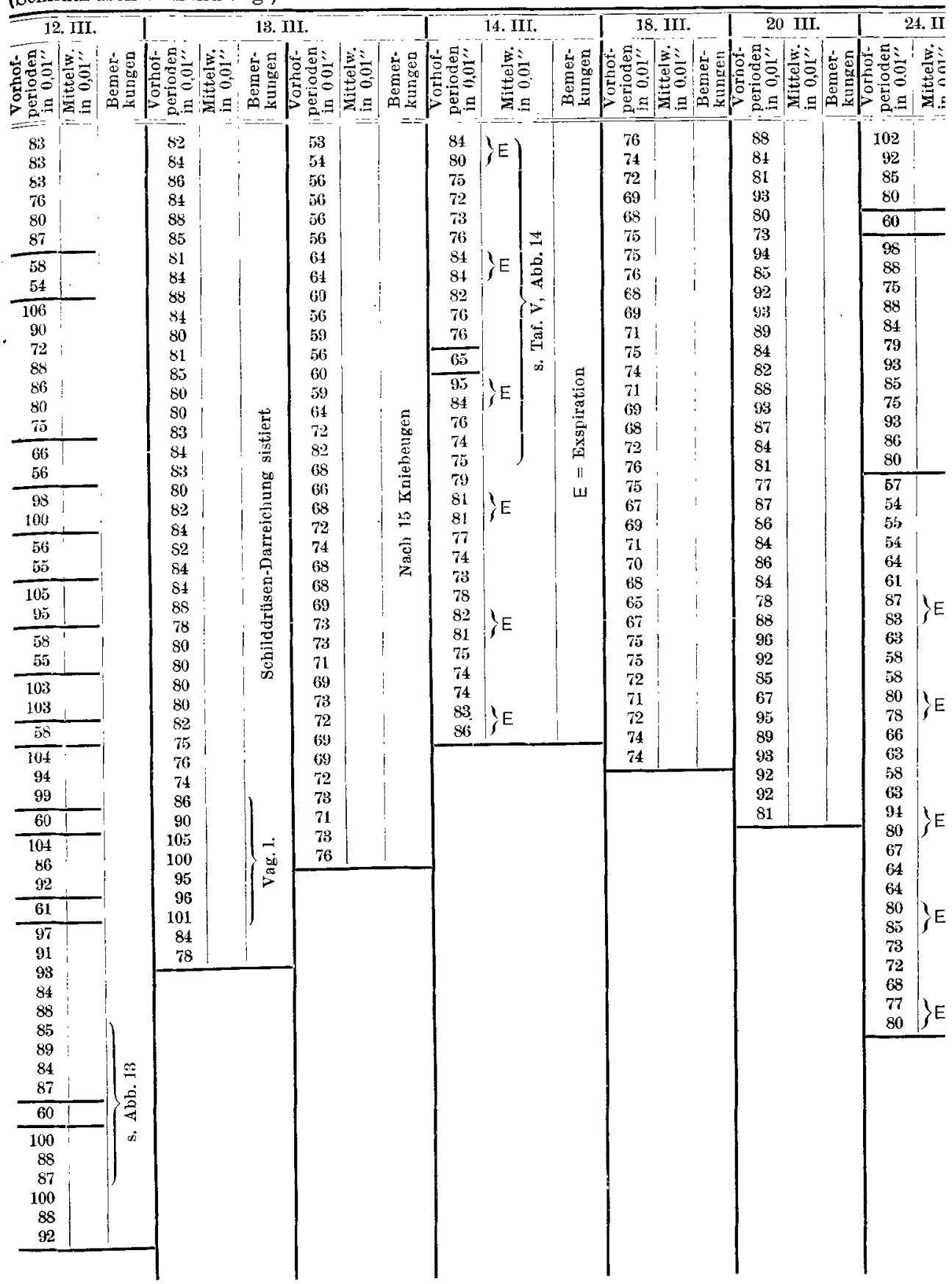


den exspiratorischen Stillstand (Abb. 14). Diese respiratorische Arhythmie findet sich in der ganzen Zeit vom 13. III.-24. III., kommt aber nur dort klar zum Ausdruck, wo die Atmung gleichmäßig, tief und langsam ist. Bei oberflächlicher, frequenter oder unregelmäßiger Respiration verwischt sich der Zusammenhang. Ebenso geht er verloren, sobald sich auch nur einzelne tachyk. Perioden zu zeigen beginnen. Dies war zum erstenmal wieder am 24. III. der Fall. Nach körperlicher Anstrengung trat mit ihrem Verschwinden sofort auch der respiratorische Charakter der Arhythmie hervor (Tab. VIII Stab 14b). Ein erster Arbeitsversuch wurde schon am 13. III. (Tab. VIII Stab 10) ausgeführt. Er hatte ein ähnliches Ergebnis wie der vom 24. IIII. und bewirkte eine annähernd ebenso starke Pulsbeschleunigung wie vor der Schilddrüsenbehandlung. Nach der Anstrengung nimmt die Schlagfrequenz allmählich $a b$, bis sie das ursprüngliche Niveau erreicht, das mit einer Minutenfrequenz von 80-90 noch innerhalb normaler Grenzen bleibt. Darin liegt wohl auch der Grund, daß sich der Patient in dem relativ langen Zeitraum vom 13. III.-24. III., während dessen, wie schon erwähnt, die Periodik gänzlich fehlt, viel leistungsfähiger fühlt, als sonst. Am 25. III. trat der Patient einen Urlaub an, von dem er am 11. IV. zurückkam. Die Periodik hatte sich inzwischen wieder vollständig ausgebildet, wie dies Abb. 3 vom 14. III. zeigt.

Die Frage, welche Vorgänge zum Wegfall der periodischen Herztätigkeit bei der Schilddrüsenbehandlung führen, ist leicht zu beantworten. Aus der Entwicklung der ganzen Erscheinungen, die mit der Verkürzung der bradyk. Perioden und dem Rudimentärwerden der tachyk. Gruppen beginnen und bis zu deren zeitweisen und schließlich endgültigen Ausbleiben fortschreiten, geht klar hervor, daß die nach dem Verschwinden der Periodik zurückbleibenden Pulse aus den bradyk. Schlägen entstanden sind. Dafür spricht ferner ihre Reaktion auf mechanische (Vagusdruck) und reflektorische Vagus- (respiratorische Arhythmie) und Acceleranserregung (Arbeit) sowie endlich das Vorkommen des sonst nur den bradyk. Perioden eigenen Formwechsels der P-Zacken.

Es ergibt sich demnach der Schluß, daß die Schilddrüsensubstanz

1. die bradyk. Perioden beschleunigt und

2. die tachyk. Gruppen unterdrückt.

Diese Verdrängung geschieht merkwürdigerweise auch hier, wie nach körperlicher Anstrengung und Lagewechsel, trotzdem die Reizbildungsfrequenz in den tachyk. Gruppen höher ist und - die rudimentären tachyk. Gruppen beweisen es - höher bleibt, als jene der schließlich zur Alleinherrschaft gelangenden, beschleunigten bradyk. Schläge. 
Chininversuche.

Das erst in neuerer Zeit in größerem Umfange in die Therapie der Herzkrankheiten eingeführte Chinin verlangsamt nach den alten Untersuchungen von Santesson ${ }^{1}$ ) und. Stokvis ${ }^{2}$ ) den Herzschlag und setzt die absolute Kraft des Herzens herab. Am meisten bekannt geworden ist die durch Wenc kebach ${ }^{3}$ ) zuerst beobachtete Beseitigung des Vorhofflimmerns durch Chinin. Auch Extrasystolen der Vorhöfe und Kammern und selbst Anfälle von paroxysmaler Kammertachysystolie können, wie dies Hecht und $\mathrm{Zweig}^{4}$ ) beschrieben und wie ich selbst bisher in jedem einschlägigen Falle (4 Beobachtungen) gesehen habe, durch Chinin vorübergehend, unter Umständen sogar dauernd aufgehoben werden. Es schien daher auch für den Gang unserer Analyse nicht ohne Wert nachzusehen, ob und wie die so scharf getrennten Perioden verlangsamter und beschleunigter Herzaktion auf Chinin ansprechen würden.

Das Ergebnis aus zwei Versuchen vom 6. XII. und 10. XII., bei denen je $0,75 \mathrm{ccm}$ Chinin. bimur. intravenös injiziert wurden, ist aus Tab. IX zu entnehmen. Die Normalwerte für den Versuch vom 10. XII. sind unter gleichem Datum in Tab. VI (Lagewechsel) eingetragen. Beide Versuche verlaufen in ähnlicher Weise so, daß in den ersten 3-4 Minuten nach der Injektion die Periodik aufhört und in der fünften Minute wiederkehrt. In beiden Versuchen ist es leider nicht geglückt, den Utbergang beim Verschwinden und Wiedererscheinen der Periodik zu registrieren. Dadurch erwachsen der Deutung der Erscheinungen im ersten Stadium große Schwierigkeiten. Dagegen bieten sich im zweiten Stadium, d. i. nach der Rückkehr der Gruppenbildung viel klarere Verhältnisse dar. Wir besprechen sie deshalb an erster Stelle.

In beiden Versuchen wird durch Chinin die Reizbildung innerhalb der tachyk. Gruppen ausgesprochen langsamer. Im Versuche vom 6. XII. messen die Reizperioden vorher im Mittel 0,53 Sek., 5 Minuten nach der Chinininjektion $0,59 \mathrm{Sek}$. Sie wachsen bis zur 20. Minute noch etwas weiter bis auf 0,6 Sek. an und nehmen nach 25 Minuten noch nicht merklich ab. Im Versuche vom 10. XII. ist der Mittelwert der tachyk. Perioden nach halbstündiger Ruhelage 0,54 Sek. (Tab. VI); während und unmittelbar nach der Injektion fällt er wohl auf 0,52 Sek.,

1) Santesson, Über die Wirkung einiger Chinaalkaloide auf das isolierte Froschherz. Archiv f. experim. Pathol. u. Pharmakol. 32, 321. 1893.

$\left.{ }^{2}\right)$ Stockvis, zit. nach Wenckebach. Berliner klin. Wochenschr. 1918, Nr. 22, S. 521 .

3) Wenckebach, Die unregelmäßige Herztätigkeit. 1914.

4) Hecht und Zweig, Über einen Fall von ventrik. Extrasystolie mit paroxysmalen Anfällen von Kammerautomatie und deren therapeutische Beeinflussung. Wiener klin. Wochenschr. 30, Nr. 6. 1917. 


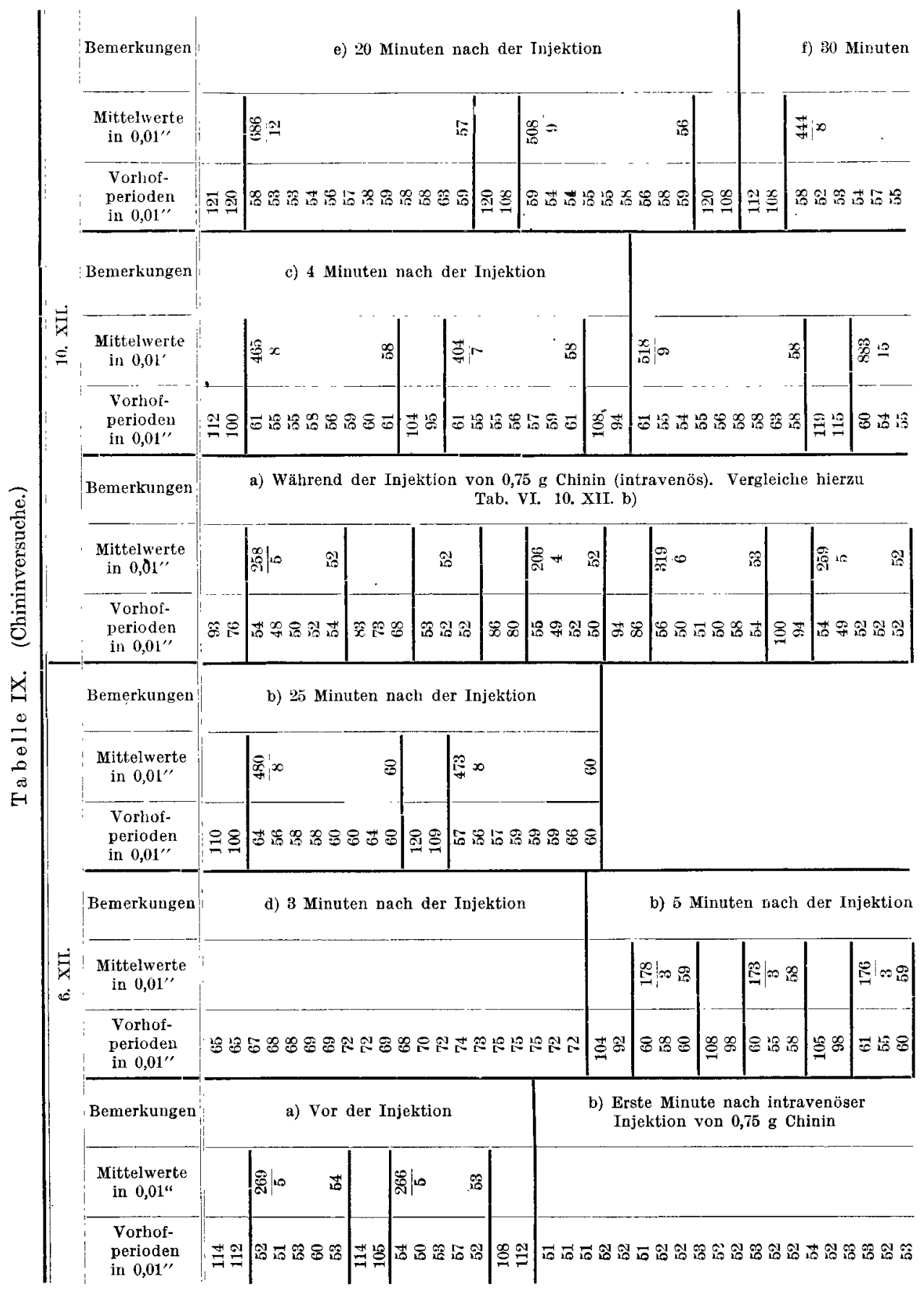




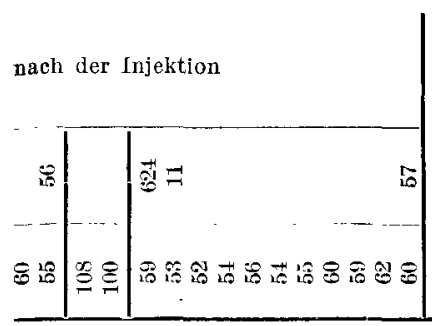

d) 10 Minuten nach der Injelition

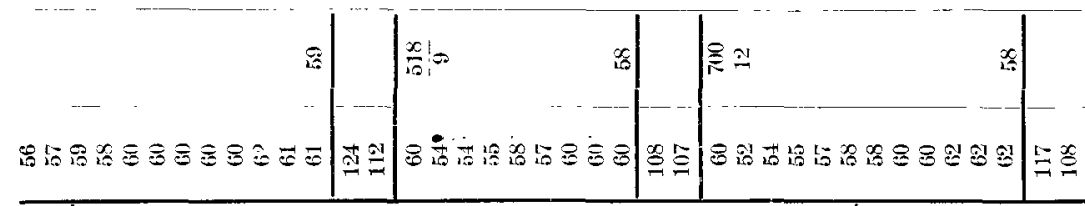

b) 3 Minuten nach der Injektion

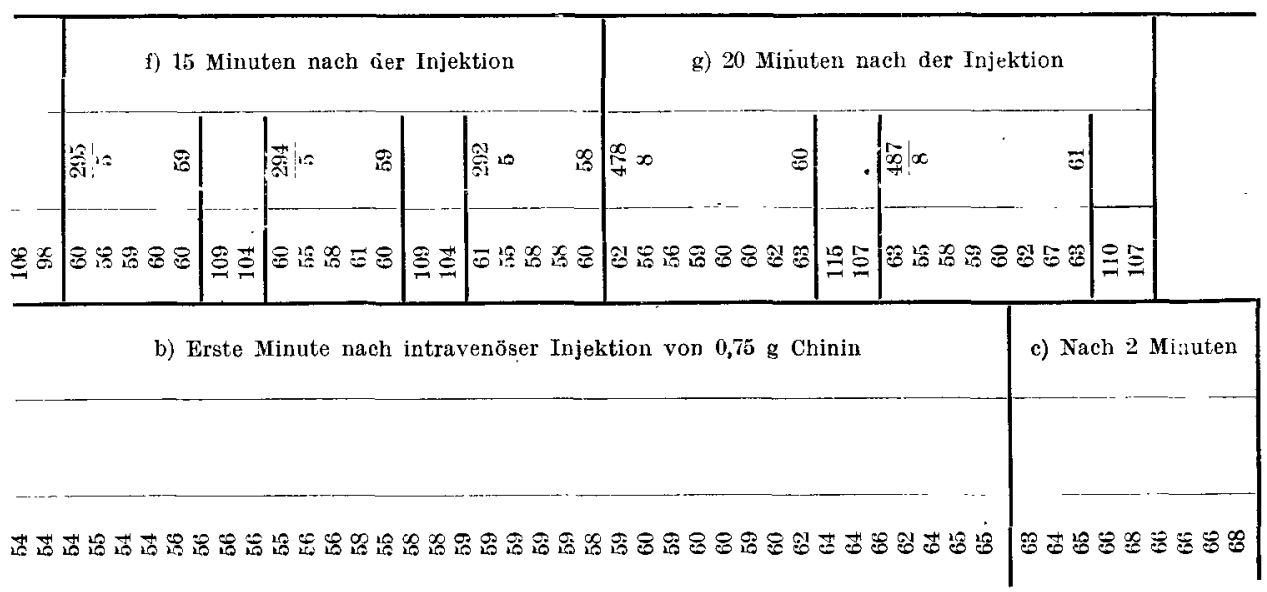


erhebt sich jedoch in der vierten Minute auf 0,58 Sek. und ist nach 30 Minuten mit $0,56-0,57$ Sek. noch deutlich größer als nach der gleich langen Ruhezeit vor der Chinininfusion.

Mit diesem, der Erwartung entsprechenden Resultate.kontrastiert um so mehr das Verhalten der bradyk. Perioden, welche nach der Chinininjektion nicht nur keine Verlangsamung, sondern im Gegenteil eine sich nur allmählich ausgleichende Beschleunigung aufweisen. Im Versuche vom 6. XII. haben die bradyk. Pulse ursprünglich einen Durchschnitt von 1,11 Sek., nach der Injektion, und zwar nach 5 Minuten von 1,01 Sek., nach 15 Minuten von 1,07 Sek. und erst nach $20 \mathrm{bzw}$. 25 Minuten wieder von 1,1 Sek. Ähnlich im Versuche vom 10. XII. Vor der Injektion ist der Mittelwert nach 30 Minuten Ruhe 1,28 Sek. (Tab. VI), unmittelbar vor und während der Injektion 0,86 Sek. Diese bedeutende Verkürzung geht zwar nach Rückkehr der Periodik zurück, und zwar in der vierten Minute auf 1,02 Sek., in der zehnten auf 1,14 Sek. und in der 20. auf 1,16 Sek. Doch ist nach 30 Minuten der Durchschnittswert der bradyk. Perioden wieder geringer und beträgt nur 1,07 Sek. Wenn wir dieser letzten Zahl auch kein weiteres Gewicht beilegen wollen, so ist doch das eine sicher, daß auch in diesem zweiten Versuche die bradyk. Perioden nach der Chinininjektion nicht länger, sondern überraschenderweise kürzer geworden sind.

Wie ist das zu erklären? Zunächst wäre an den Einfluß psychischer Erregung zu denken und dies um so mehr, als die Chininversuche in die erste Zeit des Spitalaufenthaltes fallen. Damit stimmt aber nicht recht überein, daß die bradyk. Perioden im Versuche vom 6. XII. erst nach 25 Minuten den Ruhewert erreichen und daß im zweiten Versuche auch nach 30 Minuten noch eine merkliche Verkürzung besteht. Allerdings hat die intravenöse Chinininjektion mañchmal ziemlich unangenehme Sensationen im Gefolge, die einige Zeit anhalten und einen gewissen Erregungszustand erhalten könnten. Trotzdem ist eine so lange Nachwirkung der psychischen Erregung nicht gerade wahrscheinlich. Wir erhielten aber das gleiche, der Erwartung zuwiderlaufende Resultat, als wir Herzgesunden Chinin zum weiteren Studium verabreichten. Statt der vorausgesetzten Pulsverlangsamung fand sich nach intravenöser Injektion von $0,5-1,0 \mathrm{~g}$ Chinin. bimur. sehr häufig eine manchmal gar nicht unbeträchtliche Frequenzzunahme, die zwar in den ersten Minuten am höchsten, aber auch nach 30 und manchmal selbst nach 60 Minuten noch nicht ausgeglichen war. Einige dieser Versuche liegen in Tab. X vor. Man könnte nun versucht sein, das paradoxe Phänomen der Pulsbeschleunigung nach Chinin mit ähnlichen Beobachtungen in Parallele zu stellen, nämlich damit, daß bei Vorhofflattern durch intravenöse Chinininjektionen manchmal unmittelbar schwere Anfälle von Tachykardie provoziert werden. 
Tabelle $\mathrm{X}$.

\begin{tabular}{|c|c|c|c|c|c|c|c|c|c|c|}
\hline \multirow{2}{*}{ Fall } & \multirow{2}{*}{ Diagnose } & \multirow{2}{*}{ Datum } & \multirow{2}{*}{$\begin{array}{c}\text { Dosis } \\
\text { Chinin } \\
\text { intravenos }\end{array}$} & \multirow{2}{*}{$\begin{array}{l}\text { Herzfrequenz } \\
\text { vor Chinin }\end{array}$} & \multicolumn{6}{|c|}{$\begin{array}{l}\text { Herzfrequenz nach Chinin } \\
\text { (Zelt in Minuten) }\end{array}$} \\
\hline & & & & & $1-2$ & $3-1$ & $5-10$ & -20 & -40 & -60 \\
\hline Stanick & Ulc. ventr. & 23. I. & $0,5 \mathrm{~g}$ & 66 & 70 & & 70 & 70 & 70 & \\
\hline & & 25. I. & $1,5 \mathrm{~g}$ & 72 & 105 & & 90 & 78 & 95 & 78 \\
\hline Heger & $\begin{array}{c}\text { abgelaufen } \\
\text { Jcter. catarrh. }\end{array}$ & 2. I. & $1,0 \mathrm{~g}$ & 60 & 72 & 110 & 90 & 80 & & \\
\hline Massarek & $\begin{array}{l}\text { Multiple } \\
\text { Sklerose }\end{array}$ & 9. I. & $1,0 \mathrm{~g}$ & 75 & 84 & 80 & 84 & 78 & 75 & \\
\hline$"$ & m. & 25. I. & $1,0 \mathrm{~g}$ & 75 & 100 & & 80 & 80 & 80 & 80 \\
\hline Oraves & Tachykardie & 18. I. & $1,0 \mathrm{~g}$ & 120 & 144 & & 130 & 130 & 120 & \\
\hline
\end{tabular}

Diesen ebenso seltsamen wie unangenehmen Effekt erzielte ich z. B. ganz gegen meine Absicht in jenem schon einmal erwähnten Falle. wo viele Monate hindurch unabänderlich die gleiche Flatterfrequenz von ca. 270 Vorhofkontraktionen pro Minute festgestellt werden konnte. Um die hohe Pulsfrequenz von ungefähr 135-140 Schlägen zu dämpfen, gab ich $1,0 \mathrm{~g}$ Chinin intravenös. Der Erfolg war ein ganz widersinnig erscheinender plötzlicher Anstieg der ohnehin schon hohen Pulsfrequenz auf über 200 Schläge. Gleichzeitig klagte der Patient über höchste Atemnot und es dauerte einige peinliche Minuten, bis sich Patient und Arzt von dem ausgestandenen Schrecken erholten. Die nähere Analyse ergab dann, daß die angestrebte Erniedrigung der Flatterfrequenz sogar in ausgiebigem Maße, nämlich von ca. 277 auf 205, erfolgt war, daß aber durch die plötzliche Verlangsamung der Vorhoftätigkeit der bis dahin bestandene atrioventrikuläre Block von $2: 1$ aufgehoben und in Vollrhythmus umgeschlagen war. Nach ungefähr 10 Minuten kam es allerdings wieder zur Frequenzhalbierung und damit zur Erholung. Durch interne Verabreichung von Chinin, ein Modus, der sich dieser Erfahrung zufolge bei Vorhofflattern vielleicht besser empfiehlt ${ }^{1}$ ), weil er der Kammer Zeit läßt, sich den geänderten Verhältnissen anzupassen, konnte ich die Flatterfrequenz bei diesem und anderen Kranken ohne jeden üblen Zufall ebenfalls, wenn auch nicht so ausgiebig, herabdrücken. Ich muß es mir versagen, an speziellen, ebenso schlagenden Beispielen zu zeigen, wie sehr die Tätigkeit anch anderer abnormer Reizbildungsstellen, von denen einzelne oder gehäufte Extrasystolen und selbst Anfälle von Kammerautomatie ihren Ur-

$\left.{ }^{1}\right)$ W. Frey, Weitere Untersuchungen bei absoluter Herzunregelmä Bigkeit, Berliner klin. Wochenschr, 1918, Nr, 36, S. 849, hat in einigen Fällen auch bei interner Verabreichung von Chinidin ,, noch während des Bestehens der Arhythmie" eine Steigerung der Pulsfrequenz, einmal sogar von 84 auf 134 beobachtet. Er gibt dafür keine Erklärung, es handelt sich aber offenbar um denselben Mechanismus. 
sprung nehmen, durch Chinin gehemmt wird. Indem ich mich in dieser Beziehung auf die guten Erfolge anderer, vor allem Wenckebachs stütze, glaube ich, den Schluß ziehen zu dürfen, daß Chinin zwar die normale Sinusreizbildung wenigstens vorübergehend beschleunigen kann, trotzdem aber imstande ist, die Entstehung heterotoper Erregungen zu verlangsamen und selbst a ufzuheben ${ }^{1}$ ).

Die einseitige Dämpfung der tachyk. Perioden durch Chinin wird noch augenfälliger, wenn wir die Digitaliswirkung zum Vergleiche nehmen. Hier sind auf der Höhe der Intoxikation die tachyk. Reizperioden ungefähr auf den gleichen Durchschnitt von 0,6 Sek. gelangt, hiermit parallel werden aber auch die bradyk. Schläge stark verlangsamt (Tab. VI).

Wir kehren nun zum ersten, durch das Verschwinden der Periodenbildung charakterisierten Stadium der Chininwirkung zurück und beschränken uns auf den Versuch vom 6. XII., wo dieser Teil der Beobachtung genauer durchgeführt ist. Schon in der ersten Minute nach der Injektion haben die Gruppen aufgehört. Die Herztätigkeit ist beschleunigt und ziemlich regelmäßig, wird aber nach und nach ruhiger. Die einzelnen Perioden, welche anfangs 0,51 Sek. messen, wachsen in der dritten Minute auf 0,75 Sek. an. Abermals stehen wir vor der Aufgabe, die Abstammung dieser Perioden bestimmen zu sollen, welche diesmal um so schwieriger ist, als uns, wie erwähnt, Übergangsbilder nicht zur Verfügung stehen.

Von den beiden Möglichkeiten, Verlangsamung der tachyk. und Verkürzung der bradyk. Perioden, erscheint die erstere zunächst am meisten verlockend, weil sie mit dem hemmenden Einfluß des Chinins auf die Reizbildung rechnet. Daß die tachyk. Schläge beim Einsetzen der Periodik bedeutend kürzer gefunden werden, als eben vorher am Ende des ersten Stadiums und dann, wenn auch nur wenig, wieder an Länge gewinnen, daß also die Frequenzkurve der tachyk. Schläge unter der gemachten Annahme beim Übergange des ersten in das zweite Stadium eine ihrer Richtung entgegengesetzte, scharfe Knickung aufweisen müßte, ist kein ausreichender Gegenbeweis. Denn wir haben ein ganz analoges Verhalten bei den Atropinversuchen kennengelernt, wo ebenfalls bei der Rückkehr der bradyk. Schläge die tachyk. Perioden sprunghaft beschleunigt werden. Dagegen fällt das Ausbleiben der bradyk. Gruppen schon in der ersten Minute nach der Injektion viel entscheidender ins Gewicht. In dieser Zeit, in Tab. IX, Stab 1, während

1) W. Frey hat (l. c.) bei interner Chinidin-Medikation den Sinusrhythmus bei 6 normalen Menschen unberührt gefunden und spricht sich dahin aus, daß die heterotope Reizbildung gegen Chinidin empfindlicher ist, als die Reizbildung der führenden Zentren. 
der ersten 20 Perioden, wären ja, falls es sich um tachyk. Schläge handeln würde, dieselben noch ganz unverändert. Das Verschwinden der bradyk. Gruppen bliebe daher unaufgeklärt. Nehmen wir aber an, daß die fraglichen Herzschläge durch Verkürzung der bradyk. Perioden entstanden sind, so kann es sich bei der hochgradigen Beschleunigung sofort nach der Injektion natürlich nicht um eine Chininwirkung handeln. Hier kommt nur der Einfluß psychischer Erregung in Betracht. Erst in einem etwas späteren Zeitpunkt macht sich vielleicht die früher erörterte, die Sinusreizbildung beschleunigende Komponente der Chininwirkung ebenfalls geltend. Während aber der intensive Effekt der psychischen Erregung rasch abklingt und dadurch die verdrängten tachyk. Gruppen wieder zum Vorschein bringt, hält der schwächere Einfluß des Chinins dafür um so länger an und bewirkt die paradoxe Verkürzung der bradyk. Perioden im zweiten Stadium. Freilich wäre es wünschenswert, .statt dieser vielleicht doch irrigen Überlegungen wirkliche Beweise für die vorgebrachte Auffassung zu besitzen. Nicht unerwähnt möge eine gewisse Nachwirkung des Chinins bleiben, die darin bestand, daß am folgenden Tage ohne wesentliche Änderung der Dauer der bradyk. und tachyk. Perioden die Gliederzahl der tachyk. Gruppen auch nach längerem, ruhigen Liegen auffallend klein war (2-4), ja daß sogar die tachyk. Gruppen zeitweise ganz ausblieben, so daß bis 11 bradyk. Schläge aufeinander folgten (Abb. 15).

Das Chinin verlängert demnach a usschließlich die Dauer dertachy k. Perioden, verkürzt dagegen die bradyk. Schläge. Die starke zum Verschwinden der Periodik führende Beschleunigungder bradyk. Periodengleich nach der Injektion ist keine direkte Chininwirkung.

\section{Schlußbesprechung.}

Eine zusammenfassende Diskussion der vorgelegten Versuchsergebnisse hat hauptsächlich zwei Punkte klarzustellen, erstens, ob die periodische Herztätigkeit nomotopen Ursprunges ist, oder ob sie durch Interferenz zweier Reizbildungsstellen entsteht und zweitens, nach welchem Gesetz bradyk. und tachyk. Gruppen einander ablösen.

1. Monoto pe oder bito pe Reizbildung.

Wir haben schon erwähnt, daß die P-Zacken der bradyk. und tachyk. Gruppen in ihrer Form etwas verschieden sind, daß in den bradyk. Gruppen, und zwar nur in diesen die Vorhofschwankung noch in einer zweiten Gestalt auftritt (Taf. III, Abb. 3, und Taf. V, 13 und 15), und daß die erste Periode nach den Beschleunigungsgruppen meist die längste ist. Diese Erscheinungen sprechen, wenn auch mit einem gewissen Vorbehalt, dafür, daß an der Periodik zwei verschiedene, miteinander konkurrierende Reizbildungsstellen beteiligt sind. Dazu kommt nun als weiteres Argu- 
ment das Verhalten der beiden Gruppen gegenüber nervösen und toxischen Einflüssen. Wir haben ermittelt, daß durch Reizung dér Herznerven im allgemeinen in beiden Gruppen gleichgerichtete Frequenzänderungen erzeugt werden. Durch Vagusdruck und Digitalis werden bradyk. und tachyk. Perioden verlängert, durch Acceleransreizung verkürzt. Betrachtet man aber die Stärke der erzielten Wirkung, so ergeben sich in beiden Gruppen große, mit der Art des Eingriffes wechselnde Unterschiede. Druck auf die Vagi und Acceleransreizung durch Arbeit, Lagewechsel und psychische Erregung beeinflußt z. B. vorzüglich die bradyk. Perioden, läßt dagegen die tachyk. Schläge fast unberührt. Durch Digitalis, Adrenalin und Schilddrüsensubstanz werden sowohl die bradyk, als auch die tachyk. Perioden stark betroffen.

Der Ausfall dieser Versuche spricht nicht nur dafür, daß die bradyk. und tachyk. Gruppen verschiedenen Ursprungs sind, sondern läßt weiter darauf schließen, daß die bradyk. Schläge vom Sinusknoten ausgehen. Denn der normale Schrittmacher des Herzens ist es, dessen Aktion vor allem durch die Herznerven reguliert wird und der augenscheinlich mit allen jenen zentralen Apparaten direkt verbunden ist, welche die Anpassung der Herztätigkeit an die Erfordernisse des Augenblicks vermitteln. Dagegen dürften die anderen Reizbildungsstellen mehr oder weniger außerhalb der über das Zentrum gespannten Reflexbögen liegen und aus diesem Grunde auf Nervenreize viel träger ansprechen. Von den reflektorischen Erregungen gilt dies vor allem für die Atemreflexe. Das Vorkommen von respiratorischer Arhythmíe ist meines Wissens nur bei herrschendem Sinusrhythmus bekannt. Daher ist es von Wichtigkeit, daß nach dem Verschwinden der Periodik infolge von Schilddrüsenbehandlung die übrigbleibenden, aus den bradyk. Perioden hervorgegangenen Herzschläge so deutlich respiratorische Arhythmie zeigen.

Ähnlich läßt sich vielleicht auch die verschiedene Wirkung der Acceleransreizung durch körperliche Anstrengung und durch Adrenalin auffassen; nur die letztere beschleunigt auch die heterotope Reizbildung, während erstere fast ausschließlich auf den Sinusknoten beschränkt ist. Viel schwieriger ist die analoge Differenz zwischen Vagusdruck und Digitaliswirkung zu begreifen. Ob die Flüchtigkeit der Druckerregung gegenüber der Dauerwirkung der Digitalis und eine damit vielleicht verbundene „Bahnung" die Ursache ist, warum nur diese die tachyk. Perioden ausgiebiger verlangsamt, bleibe dahingestellt. Ich möchte aber bei dieser Gelegenheit darauf hinweisen, daß das mechanische Moment beim sog. Vagusdruck nicht so ausschlaggebend ist, wie gemeinhin angenommen wird. In wiederholten Experimenten bei Hunden, Katzen und Kaninchen habe ich auch bei kräftigem Druck 
auf die vorsichtig bloßgelegten Vagi selbst nach Steigerung ihrer elektrischen Erregbarkeit durch Physostigmin immer nur sehr bescheidene Effekte und niemals längeren Herzstillstand hervorrufen können. Daß der Vagusdruck oft auch beim Menschen vollständig versagt, ist allgemein bekannt. Anderseits aber gibt es Fälle - Wenckebach (l. c. S. $167 \mathrm{ff}$.) beschreibt solche -- wo schon allerleisester Druck neben der Carotis oder bloße Berührung der Halsvagusgegend langen Herzstillstand auslöst. Unter solchen Umständen kann von einem wirklichen Druck auf den in der Tiefe so geschützt liegenden Nervenstamm kaum die Rede sein und es drängt sich der Gedanke auf, ob nicht auch hier reflektorische Einflüsse im Spiele sind. Gewiß ist auch der Zustand des Herzmuskels (Wenckebach) oder jener der Vagusendapparate ein sehr wichtiger Faktor für den Ausfall des Druckversuches und es wäre sehr wohl möglich, daß durch Digitalis an der heterotopen Reizbildungsstelle erst die Bedingungen für ein kräftigeres Eingreifen der Hemmungsnerven geschaffen werden.

Wie dem nun auch sei, jedenfalls sprechen die genannten Eingriffe für die Verschiedenheit des Reizursprunges in den bradyk. und tachyk. Gruppen. Noch mehr aber scheint dies die Chininwirkung zu beweisen. Denn unter der Voraussetzung, daß das Chinin direkt an den Reizbildungsstellen angreift, gibt es für diese Folgerung kaum ein schlagenderes Argument als die Tatsache, daß der durch dieses Mittel erzielte Ausschlag in beiden Gruppen nicht mehr gleichsinnig, sondern entgegengesetzt gerichtet ist. Bevor man jedoch den bindenden Schluß zieht, daß das Chinin in Dosen, welche die untergeordneten Zentren bereits schädigen, den Sinusknoten zu erregen vermag, wäre es notwendig durch entsprechend eingerichtete Tierexperimente die Möglichkeit einer zentralen Chininwirkung auszuschließen. Könnte doch auf diesem Wege ein das Sinustempo, wenn auch weniger stark dämpfender Einfluß des Chinins verschleiert werden. Wenigstens haben $\mathrm{Hecht}$ und Rothberger ${ }^{1}$ ) am normal schlagenden Herzen sowohl bei intravenöser wie auch bei lokaler Applikation auf den Sinusknoten eine Herabsetzung der Frequenz nachgewiesen. Mit der Auffassung der bradyk. Perioden als normaler Sinussehläge und der tachyk. Gruppen als heterotop automatischer Reihen stimmen auch die Frequenzverhältnisse überein. Die Minutenfrequenz der brachyk. Schläge ist zwar niedrig, liegt aber noch innerhalb normaler Grenzen, wogegen die tachyk. Schläge diese bedeutend überschreiten. Eine überfr equente Reizbildung der untergeordneten Zentren ist aber eine der Grundbeding ungen für das reihenweise Hervortreten a utomatischer Kontraktionen.

1) Hecht und Rothberger, Experimentelle Beiträge zur Kenntnis der Chininwirkung bei Herzflimmern. Zeitschr. f. d. ges. exp. Med. $\boldsymbol{\gamma}$, Heft 3. 
In scheinbarem Widerspruch zu der eben erwähnten geringen Beeinflußbarkeit der tachyk. Perioden durch Vagusreizung steht die früher beschriebene Tatsache, daß die tachyk. Gruppen durch Druck auf die Vagi plötzlich abzureißen pflegen. In analoger Weise sieht man aber auch ventrikuläre, nach der Form des Elektrogramms von den tertiären Zentren ausgehende Extrasystolen auf Vagusdruck vorübergehend verschwinden, obwohl sonst ein Einfluß der Hemmungsnerven auf diese untergeordneten Reizbildungsstellen nicht nachweisbar ist. Ich stütze mich dabei auf Erfahrungen von Wenckebach und auf viele eigene Befunde, die ich namentlich bei kontinuierlicher Bigeminie und anderen allorhythmischen Extrasystolien erhoben habe. Von dem Gedanken ausgehend, daß diese Formen von Allorhythmie durch Interferenz des normalen mit einem pathologischen Rhythmus bedingt sein könnten, machte ich immer wieder den vergeblichen Versuch, durch Druck auf die Vagi die Sinusschläge zu unterdrücken, um so die automatische Kammertatigkeit rein zur Anschauung zu bringen. Allgemein bekannt ist übrigens die gleichfalls hierher gehörige Tatsache, daß Anfälle paroxysmaler Tachykardie durch Vagusdruck coupiert werden können. Das alles läßt sich vielleicht in verhältnismäßig einfacher Weise durch bathmotrope Einflüsse erklären. Nimmt man an,. da $B$ die extrasystolischen bzw. automatischen heterotopen Reize gerade noch zureichend sind, so können sie, sobald die Erregbarkeit durch Vagusreizung abnimmt, leicht unterschwellig werden. So ist es auch in unserem Falle möglich, daß die tachyk. Gruppen während einer Vagusreizung abbrechen, ohne daß̣ die einzelnen Perioden vorher verlangsamt werden, da nur die primär chronotrope Wirkung an bestimmte Einstrahlungspunkte der Herznerven in das spezifische Muskelsystem gebunden ist, während den bathmotropen Einflüssen die gesamte Herzmuskulatur unterworfen zu sein scheint.

\section{Die Ursache der Gruppenbildung.}

Wenn wir so dazu gelangt sind, die periodische Herztätigkeit auf die Interferenz der nomotopen mit einer heterotopen Reizbildungsstelle zurückzuführen, so sind wir damit dem Verständnis der Gruppenbildung scheinbar um nichts näher gekommen. Im Gegenteil, wir haben uns die so bequeme Annahme abgeschnitten, welche die Periodik aus rhythmischen Schwankungen in der Tätigkeit eines einzigen Reizbildners entspringen läßt. Wie aber ist es zu erklären, daß in gleichem Wechsel bald das langsamer arbeitende Hauptzentrum im Sinusknoten, bald das rascher tätige Nebenzentrum dem Herzen sein Tempo aufzwingt? Indem wir diese Frage aufwerfen, treten wir an ein sehr interessantes Problem heran, dessen Lösung vor allem eine ungezwungene Antwort auf die immer wieder sich aufdrängende Frage erheischt, warum die 
langsameren Sinusreize von Zeit zu Zeit in regelmäßigen Abständen die frequenteren Extrareize überwinden.

An dem Gesetze, daß die frequenteren Erregungen (ceteris paribus) dem Herzen ihr Tempo diktieren, läßt sich nicht rütteln. Daß aber das automatisch arbeitende heterotope Zentrum seine Tätigkeit in immer gleichen Intervallen einstellen und wiederaufnehmen sollte, um seine Ruhepausen dem Sinusknoten zur Verfügung. zu stellen, ist mir äußerst unwahrscheinlich, und zwar vornehmlich deshalb, weil während der manifesten Tätigkeit des Nebenzentrums gar keine Zeichen seiner Erschöpfung wahrnehmbar sind. Robinson und Draper ${ }^{1}$ ), die vor Jahren einige dem hier beschriebenen Falle offenbar nahe verwandte Beobachtungen mitgeteilt haben, nehmen indessen eine solche periodische Ermüdung der heterotopen Reizbildungsstelle an, und zwar ungeachtet des Umstandes, daß, wie sie sagen , it is evident that the rate of stimulus formation gradually increases until for some reason the abnormal stimuli suddenly cease. This sudden cessation", fahren sie fort, ,,suggests that fatigue sets in and that rest is necessary before the function of stimulus formation can be resumed. It is probable, therefore, that a rhythmic alteration in the excitability occurs in thome auricular region which is capable of generating stimuli, and that the change in excitability is determined by periods of rest and fatigue of the heart muscle itself." Von dem, wie ich glaube, richtigen Gedanken, im Mechanismus des Herzens und $n$ ur in diesem die Ursache der Periodenbildung zu suchen, weichen die Autoren ab, indem sie den extrakardialen Nerven eine, wenn auch nicht ausschließliche, so doch wichtige Rolle bei der Entstehung des rhythmischen Schlagwechsels zuschreiben. Gewiß können die Herznerven die Periodik weitgehend modifizieren, wofür wir ja zahlreiche Beispiele beigebracht haben. Trotzdem erscheint mir jeder Versuch die Gruppenbildung selbst auf Nerveneinflüsse - sei es nun auf eine periodische Hemmung oder Erregung der heterotopen Reizbildungsstelle durch die Vagi bzw. Accelerantes - zurückführen zu wollen, schon an der bei ruhigem Verhalten des Untersuchten so vollkommenen GleichmäBigkeit der Periodik scheitern zu müssen.

Auch eine Blockierung der abnormen Reize im gewöhnlichen Sinne kann nicht vorliegen. Denn dann müßten zum mindesten die ganzen Intervalle zwischen je zwei tachyk. Gruppen durch die tachykarde Reizperiodendauer ohne Rest teilbar sein. Daß sie es aber nicht sind, spricht dafür; daß der Sinusrhythmus den heterotopen Rhythmus stört. Umgekehrt müssen aber auch die tachyk. Impulse, sobald sie dominieren, die Sinusreizbildung beeinflussen. Es geht dies unmittel-

1) Robinson u. Draper, Rhythmic changes in the human heart beat. Heart. 4, 97. 1912. 
bar daraus hervor, daß die erste bradyk. Periode oder richtiger der letzte Schlag der tachyk. Gruppe in gleichen Kurvenstücken annähernd dieselbe Dauer aufweist. Das ist nur möglich, wenn die letzte heterotope Erregung rückläufig das an normaler Stelle bereits entstandene Reizmaterial zerstört und so den Beginn seiner Neubildung auf diesen Augenblick festlegt. Unter anderen Umständen wäre die erste bradyk. Periode von sehr variabler Länge, weil sie-nach dem letzten tachyk. Schlage und wiedererlangter Erregbarkeit in jedem beliebigen Momente erfolgen könnte.

Da also die beiden Zentren, die wohl auch räumlich nicht allzu weit auseinanderliegen dürften, sich gegenseitig in ihrer Tätigkeit beeinflussen, muß der Weg zwischen ihnen offen sein.

In Erwägung aller dieser Umstände bin ich schließlich dazu gelangt, auf das Verhältnis von Reizstärke und Erregbarkeit zurückzugreifen. Damit glaube ich noch am ehesten zu einer annehmbaren Erklärung der Gruppenbildung kommen zu können. Angenommen, es wäre diè Stärke des heterotopen Reizes geringer als die des nomotopen und liege dabei nicht weit über dem Schwellenwerte, so kann während der tachyk. Gruppen eben wegen der raschen Schlagfolge die Erregbarkeit allmählich so tief sinken, daß die extrasystolischen Reize unzureichend werden. Erst nach einer Pause, innerhalb welcher sie den noch über der Schwelle liegenden stärkeren, aber langsameren Sinuserregungen die Herrschaft abtreten müssen, können sie wieder die Führung an sich reißen. Mit dieser Auffassung steht das unvermittelte Einsetzen und Abbrechen der beiden Gruppen in Einklang, da sich ja die allmähliche Erregbarkeitsabnahme im elektrographischen Bilde nicht abzeichnet.

Im Grunde genommen ist diese ganze Vorstellung nichts anderes, als die alte Wenckebachsche Theorie vom Systolenausfall durch Erregbarkeitsstörung nur mit dem Unterschiede, daß sie hier auf Reize heterotopen Ursprungs angewendet ist und daß größeres Gewicht auf die Relativität des Erregbarkeitsbegriffes d. h. auf das Verhältnis von Reizstärke und Reizbarkeit gelegt wird. Und weiter sind wir durch diese Utberlegung ganz unbeabsichtigt zu der schon einmal erörterten und dort fast abgewiesenen Möglichkeit zurückgelangt, daß ausfallende heterotope Vorhofsystolen mit interpoliertem Sinusrhythmus die Ursache der Periodenbildung sind.

Den direkten Beweis für den Ausfall heterotoper Vorhofkontraktionen konnten wir allerdings nicht erbringen. Es wurde schon darauf hingewiesen, daß dieser Versuch, abgesehen von den Unregelmäßigkeiten der heterotopen Schläge, wahrscheinlich daran scheitert, daß die eingeschalteten Normalschläge den heterotopen Rhythmus stören. Darüber darf man sich nicht täuschen, auch wenn in größeren Kurvenstrecken und selbst an einem oder dem anderen Tage die Ubereinstimmung 
der Summe der interpolierten Sinusschläge mit einem Vielfachen der heterotopen Perioden den strengsten Anforderungen entspricht. Denn dieser scheinbaren Ưbereinstimmung läuft zu anderen Zeiten eine offenkundige Diskrepanz parallel, die durch eine ad hoc gemachte Annahme nicht aus der Welt zu schaffen ist. Utbrigens bedarf es nur dort, wo das heterotope Tempo hinter dem Sinustempo zurückbleibt, einer besonderen Erklärung dafür, daß dieses das erstere nicht unterdrückt. Kaufmann und Rothberger sprechen in diesen Fällen von einer ,Schutzblockierung", ein trefflicher Ausdruck, der sagen will, daß die abnorme Reizbildungsstelle den vom Sinus ausstrahlenden Erregungen unerreichbar ist. In unserem Falle und überall, wo das heterotope Tempo schneller ist als das nomotope, ist indessen diese Annahme nicht notwendig. A ufklärung fordert dagegen das zeit weise Unwirksamwerden dervom untergeordnetenZentrum a usgesandten frequenteren Reize. Stoßen vielleicht auch diese auf einen unüberschreitbaren Damm, auf den ,Block gegen das Myokard" von Ka ufmann und Rothberger? Wenn ich dieses Hindernis, man könnte ès ,Emissionsblock" nennen, weiter in die Peripherie, in die nach einer Reihe allzu rascher Kontraktionen erschöpfte Muskulatur verlege und als rein funktionell ansehe, so unterscheidet sich meine Auffassung vielleicht nur um eine Nuance von jener der genannten Autoren. Natürlich habe ich keinen Grund, dem sonst gesunden und leistungsfähigen Herzmuskel meines Patienten eine unternormale Erregbarkeit zuzuschreiben, sondern beziehe sein temporäres Versagen auf die absolut niedrige, kaum den Schwellenwert übersteigende Stärke der überfrequenten, jedoch des ,energetischen Reizüberschusses " entbehrenden, krankhaften Erregungen.

Ich stelle mir dabei vor, daß die Überschwelligkeit des normalen Leitungsreizes durch eine geringere Erregbarkeit der den Reiz bildenden bzw. direkt aufnehmenden Sinusmuskulatur bedingt ist, und erblicke in dieser oder einer anderen, ähnlichen Einrichtung in Übereinstimmung mit A l c o ck und Me yer $\mathbf{r}^{1}$ ) eine wichtige Sicherung für den ungestörten Betrieb des Herzens, der sonst durch jede geringe Erregbarkeitsschwankung in Frage gestellt wäre.

Die aufgestellte $\mathrm{Hypothese} \mathrm{wurde} \mathrm{zunächst} \mathrm{auf} \mathrm{die} \mathrm{spontane} \mathrm{Perioden-}$ bildung zugeschnitten. Ist sie aber mehr als eine bloße Umschreibung der Tatsachen, trifft sie auch das innere Wesen der ganzen Erscheinung? Paßt sie also auch auf jene Veränderungen, welche die Periodik in unseren Versuchen unter dem Einflusse der verschiedenen Eingriffe erleidet? Wie kann es insbesondere geschehen, daß der etwas beschleunigte, aber immer noch hinter dem frequenteren extrasystolischen zurückbleibende Sinusrhythmus jenen vollständig verdrängt, wie wir das wiederholt zu unserer Verwunderung gesehen haben. Um diese

1) Alcock und H. Meyer, Uber die Wirkung des Carpains auf die Herztätigkeit. Arch. f. Anat. u. Phys., Phys. Abt. 1903, S. 225. 
Frage beantworten zu können, müssen wir wissen, wie sich in unserem Schema die beiden Zentren, von denen das eine langsamere und stärkere, das andere häufigere, aber schwächere Erregungen aussendet, bei Änderungen der Reizfrequenz gegenseitig beeinflussen. Nehmen wir zunächs̀t an, daß nur die Reizbildungsfrequenz des Sinusknotens wachse, so werden die normalen Reizperioden und damit die Erholungspausen immer kürzer und in einem bestimmten Momente so kurz werden, daß die Erregbarkeit nicht mehr bis zu der Höhe ansteigen kann, bei welcher die von dem heterotopen Zentrum emittierten schwächeren Erregungen wirksam werden können. In diesem Augenblicke wird die Gruppenbildung aufhören und der Sinusknoten wird trotz seiner absolut niedrigeren Frequenz dominieren. Bevor noch dieser Grenzfall erreicht wird, sowie bei geringeren Graden der Sinusbeschleunigung werden die extrasystolischen Reihen immer mehr an Gliedern verlieren. Beim Abklingen der Wirkung werden sie umgekehrt zuerst mit sehr reduzierter, nach und nach wachsender Gliederzahl zurückkehren. Ist es nur Zufall, daß sich nach körperlicher Anstrengung, Lagewechsel und in besonders übersichtlicher Entwicklung bei der Schilddrüsenbehandlung die angeführten Erscheinungen genau in derselben Reihenfolge abrollen und daß in all den genaninten Fällen fast ausschließlich die bradyk. Perioden verkürzt, d. h. die Sinusreize beschleunigt werden? Nur die Adrenalinversuche, bei denen ja ebenfalls der Herzsympathicus betroffen wird, machen eine Ausnahme. Hier geht die Periodik wenigstens bei den angewendeten Dosen und innerhalb der vielleicht allzu kurzen Beobachtungszeit nicht verloren. Dafür fehlt aber auch eine wesentliche Beschleunigung der Sinusperioden, wohl aber sind die tachyk. Schläge verkürzt. Zunehmende Frequenz der Extrareize führt jedoch im Rahmen unserer Hypothese zunächst zur Gruppenverkürzung, dann zu kontinuierlicher Bigeminie, zu Trigeminie und schließlich vielleicht zu anderen Formen von Extrasystolie. Mit der Behauptung, daß auch der Erfolg der Vagusreizung unserer Auffassung nicht widerspricht, gehen wir wohl nicht zu weit. Ein Einwand, der etwa erhoben werden könnte, wäre der, daß der starken Verlangsamung der bradyk. Perioden wegen der längeren Erholungszeit gliederreichere tachyk. Gruppen folgen sollten, während wir umgekehrt ihr vorzeitiges Abbrechen festgestellt haben. Dieser Einwand wäre berechtigt, wenn der Vagusdruck nur die Sinusfrequenz und sonst nichts ändern würde. Er hemmt aber auch Reizleitung und Anspruchsfähigkeit, wofür wir in der Verlängerung des $\mathbf{P}-\mathbf{R}$-Intervalles, im Kammersystolenausfall und speziell in dem chronotrop unvermittelten Abreißen der tachyk. Gruppen handgreifliche Dokumente besitzen. Wo so viele Komponenten am Endresultate mitwirken, wird dieses von den jeweils überwiegenden Einflüssen diktiert sein und daher je 
nach Umständen verschieden ausfallen. Beim einfachen Vagusdruck entscheiden offenbar chronotrope Hemmung auf der einen, Herabsetzung der Erregbarkeit auf der anderen Seite, diese für die Verkürzung der tachyk. Gruppen, jene für die Verlangsamung der Sinusperioden. Anders schon bei der toxischen Vagusreizung durch Digitalis! Hier wird auch die heterotope Reizbildung verzögert. Damit wird gerade jener Faktor, welcher die Erregbarkeit so bald erschöpft und mit der negativ bathmotropen Vaguswirkung zusammenstimmt, entscheidend geschwächt. Jetzt erst wird die Verlängerung der Erholungszeit in den langsamen Sinusperioden ausschlaggebend und die erwartete Entstehung vielschlägiger tachyk. Gruppen tritt ein. Noch ein Schritt auf diesem Wege und wir würden zur Unendlichkeit der extrasystolischen Reihen gelangen. Denn es ist klar, daß der Sinusrhythmus durch die rascheren Extrareize vollständig verdrängt werden muß, sobald diese ihr Tempo nur so weit mäßigen, daß sie das Niveau der Erregbarkeit in keiner Phase mehr unter die Schwelle ihrer Reizstärke herabdrücken. Dieser wohlbekannte zweite Grenzfall, bei dem also der raschere Rhythmus den langsameren überwindet und der ebenfalls an ein bestimmtes Verhältnis der verschiedenen Grundqualitäten Engelmanns gebunden ist, scheint bei der Ausschaltung des durch Digitalis erhöhten Vagustonus mittels Atropin durchlaufen zu werden.

Ich verzichte darauf, noch andere unserer Versuchsergebnisse in dieser Weise zu rekonstruieren, weil die Gefahr sehr groß ist, im Hinblicke auf ein praktisch gegebenes Endresultat die verschiedenen Faktoren mit ihren klinisch unübersehbar verwickelten, sekundären Rückwirkungen so zu gruppieren, daß sich schließlich das gewünschte, dem Kausalitätsbedürfnis entsprechende Resultat ergißt.

Sicherlich verdienen aber die Variationen der Reizstärke bei den Störungen des Herzrhythmus größere Aufmerksamkeit, als ihnen bislang zuteil wurde. Sie werden besonders dort im Auge zu behalten sein, wo verschiedene Reizbildungsstellen in Wettbewerb treten. Ihre Bedeutung könnte vielleicht auch bei der Beurteilung anderer Formen von Extrasystolien von Bedeutung sein. Die eigentümliche Labilität der vereinzelt auftretenden Extrasystolen, ihr merkwürdiges Verschwinden bei Vagusdruck sowie auch unmittelbar nach körperlicher Anstrengung erinnert sehr an das Verhalten unserer extrasystolischen Reihen und beruht vielleicht auf der gleichen Ursache, der ,,relativen Schwäche der heterotopen Reize", einem allgemeineren Gesetz, das sich in unserem besonderen Falle nur etwas klarer rückspiegelt ${ }^{1}$ ).

1) Ka ufmann und Rothberger haben inzwischen in ihrer während der Drucklegung dieser Mitteilung erschienenen Arbeit (Beiträge zur Entstehungsweise extrasystolischer Allorhythmien, 3. Mitteilung, diese Zeitschr. IX, 104, 1919) ebenfalls auf die Bedeutung der Stärke des Extrareizes Rücksicht genommen. 
168 H. Winterberg: Zur Kenntnis und Analyse der period. Herztätigkeit usw.

Zusammenfassung.

Es wird ein durch 8 Monate beobachteter Fall von periodischer Herztätigkeit beschrieben, der durch den regelmäßigen Wechsel von Gruppen verlangsamter und beschleunigter Herzschläge gekennzeichnet ist.

Die elektrographische Analyse der Allorhythmie beweist zwar ihren supraventrikulären Ursprung und läßt ihre Entstehung durch respiratorische Arhythmie oder periodischen Vorhofsystolenausfall unmittelbar ausschließen, ist aber für sich allein nicht ausreichend, um zu entscheiden, ob die beiden Gruppen von Herzschlägen aus einem einzigen (,Lucianische Perioden") oder aus zwei Reizbildungspunkten hervorgehen.

Es wird versucht, diese Frage dadurch zu beantworten, daß der Einfluß verschiedener Eingriffe auf die beiden Gruppen bradyk. und tachyk. Herzschläge gesondert festgestellt wird.

Insbesondere werden studiert: die Wirkung mechanischer und toxischer Vaguserregung (Vagusdruck und Digitalis), der Vagusausschaltung (Atropin), der reflektorischen und toxischen Acceleransreizung (körperliche Anstrengung, Lagewechsel, psychische Erregung, Adrenalin), ferner der Einfluß einer Schilddrüsenbehandlung und die Wirkung von Chinin.

Aus diesen Experimenten, die eine gewöhnlich nur dem Grade, manchmal (Chinin) aber auch der Richtung nach verschiedene Beeinflußbarkeit der bradyk. und tachyk. Perioden ergeben, wird der Schluß gezogen, daß die bradyk. Schläge nomotopen, die tachykarden dagegen heterotop-automatischen Ursprungs sind.

Die Gruppenbildüng d. h. der rhythmische Wechsel der bradyk. und tachyk. Perioden wird durch die Annahme zu erklären versucht, daß das rascher tätige Nebenzentrum relativ schwache, nicht weit über dem Schwellenwerte liegende Erregungen aussendet und daß dann während der tachyk. Schläge infolge ihrer schnellen Aufeinanderfolge die Anspruchsfähigkeit so weit absinkt, daB die extrasystolischen Reize unzureichend werden. Erst nach einer Pause, innerhalb welcher die stärkeren, aber langsameren Sinuserregungen zur Geltung kommen, wächst die Erregbarkeit wieder zu dem Grade an, die das Erscheinen einer neuen tachyk. Gruppe ermöglicht.

Es wird die Vermutung geäußert, daß auch bei der gewöhnlichen Form der Extrasystolie die pathologischen Reize relativ schwach sind und daß auf diesem Umstande ihr vereinzeltes Auftreten und ihre verhältnismäßig leichte Unterdrückbarkeit beruht. 